Article

\title{
Arabidopsis Toxicos en Levadura 12 (ATL12): A Gene Involved in Chitin-Induced, Hormone-Related and NADPH Oxidase-Mediated Defense Responses
}

\author{
Feng Kong ${ }^{1} \mathbb{( D}$, Tingwei Guo ${ }^{2}$ and Katrina M. Ramonell ${ }^{1 \text {,* }}$ \\ 1 Department of Biological Sciences, The University of Alabama, Tuscaloosa, AL 35401, USA; \\ fkong@crimson.ua.edu \\ 2 Center for Craniofacial Molecular Biology, University of Southern California, Los Angeles, CA 90089, USA; \\ tingweig@usc.edu \\ * Correspondence: kramonel@ua.edu
}

Citation: Kong, F.; Guo, T.; Ramonell, K.M. Arabidopsis Toxicos en Levadura 12 (ATL12): A Gene Involved in Chitin-Induced, Hormone-Related and NADPH Oxidase-Mediated Defense Responses. J. Fungi 2021, 7, 883. https://doi.org/10.3390/ jof7100883

Academic Editor: Kuang R. Chung

Received: 1 September 2021

Accepted: 16 October 2021

Published: 19 October 2021

Publisher's Note: MDPI stays neutral with regard to jurisdictional claims in published maps and institutional affiliations.

Copyright: (c) 2021 by the authors. Licensee MDPI, Basel, Switzerland. This article is an open access article distributed under the terms and conditions of the Creative Commons Attribution (CC BY) license (https:// creativecommons.org/licenses/by/ $4.0 /)$.

\begin{abstract}
Plants, as sessile organisms, have evolved complex systems to respond to changes in environmental conditions. Chitin is a Pathogen-Associated-Molecular Pattern (PAMP) that exists in the fungal cell walls, and can be recognized by plants and induce plant pattern-triggered immunity (PTI). Our previous studies showed that Arabidopsis Toxicos en Levadura 12 (ATL12) is highly induced in response to fungal infection and chitin treatment. We used the model organism Arabidopsis thaliana to characterize ATL12 and explore its role in fungal defense. Histochemical staining showed that $p$ ATL12-GUS was continually expressed in roots, leaves, stems, and flowers. Subcellular colocalization of the ATL12-GFP fusion protein with the plasma membrane-mcherry marker showed that ATL12 localizes to the plasma membrane. Mutants of atl12 are more susceptible to Golovinomyces cichoracearum infection, while overexpression of ATL12 increased plant resistance to the fungus. ATL12 is highly induced by chitin after two hours of treatment and ATL12 may act downstream of MAPK cascades. Additionally, 3,3'-diaminobenzidine (DAB) staining indicated that atl12 mutants generate less reactive oxygen species compared to wild-type Col-0 plants and RT-PCR indicated that ATL12-regulated ROS production may be linked to the expression of respiratory burst oxidase homolog protein $D / F(A t R B O H D / F)$. Furthermore, we present evidence that ATL12 expression is upregulated after treatment with both salicylic acid and jasmonic acid. Taken together, these results suggest a role for ATL12 in crosstalk between hormonal, chitin-induced, and NADPH oxidase-mediated defense responses in Arabidopsis.
\end{abstract}

Keywords: chitin; fungal defense; plant hormone; NADPH oxidase; Arabidopsis thaliana; Golovinomyces cichoracearum

\section{Introduction}

In nature, plants are exposed to various environmental stresses such as pathogen attack (fungi, bacteria, insects, etc.) and abiotic stress (heat, salt, drought, etc.). Such environmental stressors are common conditions that directly affect plant metabolism, resulting in changes in gene expression and altering plant growth and development [1] Due to climate change and global food distribution patterns, fungal pathogens pose an increased threat to current and future food security [2]. Worldwide, there are over 500 powdery mildew species that colonize over 10,000 different plant species and are the cause of significant crop losses, especially to plants in the Cucurbitaceae (cucurbits) and Vitaceae (grape) families [3,4]. Once disease develops, large numbers of asexual spores are formed, spreading the infection to the whole plant and then via wind dispersion to surrounding plants [4]. As biotrophic pathogens, powdery mildews acquire nutrients from their host plants through a specialized feeding structure, the haustoria. The redirection of photosynthate and other critical resources to the spreading fungal infection results in a 
reduction in overall crop yield and losses in fruit and/or vegetable product quality $[3,5]$. By elucidating the signaling transduction mechanisms initiated upon powdery mildew infection, practical solutions may be uncovered for the control of plant fungal disease in crops $[5,6]$.

Although plants face numerous pathogen attacks in nature, they have evolved efficient immune responses to protect themselves from disease. Generally, pathogens are recognized by Pathogen-Associated-Molecular Patterns (PAMPs) in plants [5]. The detection of PAMPs by plant pattern recognition receptors (PRR), induces a defense response called patterntriggered-immunity (PTI) [1]. There are several different types of PAMPs, including bacterial flagellin [7], chitin and its derivatives [8], the secretory protein OPEL [9], and bacterial elongation factor 2 [5]. These PAMPs are recognized by their corresponding PRRs, including the Arabidopsis flagellin sensitive 2 (FLS2) receptor, LysM-domain-containing receptor-like kinase 1 (RLK1)/chitin-elicitor receptor kinase 1 (CEBiP), and the Arabidopsis EF-Tu receptor $[5,6]$. After a pathogen is recognized, a number of defense mechanisms are induced, such as the closure of leaf stomata, the generation of reactive oxygen species [10], the hypersensitive response (HR), and the production of defense-related proteins [7].

Chitin, a polysaccharide that is composed of $\mathrm{B}-1-4$-linked $\mathrm{N}$-acetylglucosamine, is a PAMP, which exists in fungal cell walls and insect exoskeletons [11]. Plants do not contain chitin, but they do produce chitin degrading enzymes (chitinases) that can digest fungal cell walls leading to the release of small chitin fragments that then function as PAMPs, eliciting a defense response [9]. In Arabidopsis, LysM-receptor-like kinases AtCERK1, and AtLYK5/AtLYK6 form a chitin receptor complex, which are able to detect chitin and induce chitin-triggered immunity [12-15]. In rice, during fungal infection, chitin fragments are detected by CEBiP (chitin elicitor binding protein), a LysM domain-containing protein [12-15]. CEBiP does not have an intracellular domain, so the recognition of chitin clearly required the assistance of a "partner" receptor-like kinase or receptor-like protein [14]. In subsequent work, the LysM RLK1/chitin-elicitor receptor kinase 1 (OsCERK1) complex was found to play a critical role in chitin recognition [16]. After chitin recognition, both AtCERK1/AtLYK5/AtLYK6 complex and the OsCERK1/CEBiP complex are able to activate a MAPK cascade and induces the expression of several transcription factors downstream in the chitin signaling pathway. These transcription factors regulate the expression of defense-related genes, leading to disease resistance $[4,13]$. Based on the latest evidence, it seems that the chitin signaling pathway and the bacterial flagellin and EF-Tu induced signaling pathways all share common downstream elements [14]. The recognition of all three elicitors: chitin, bacterial flagellin, and elongation factor-Tu induce the same MAPK kinase cascade and leads to the expression of WRKY transcriptional factors and other defense-related proteins [17].

The Ubiquitin/26S proteasome system plays an important role in degrading misfolded proteins and in regulating signals in plant innate immunity [17]. Additionally, the Ubiquitin/26S proteasome system is involved in many significant processes, including cell division, plant growth and development, plant-pathogen interactions, plant hormone responses, and biotic and abiotic stress resistance (cold, salt, and drought) [18,19]. In the Arabidopsis genome 2 E1 ubiquitin-activating enzymes, 37 E2 ubiquitin-conjugating enzymes, and 1415 E3 ubiquitin ligases are encoded [11]. Generally, E3 ubiquitin ligases can be divided into two main groups, based on their specific structure. The first are the Homology to E6-AP C-terminus (HECT) domain-containing E3 Ubiquitin ligases, containing seven distinct gene categories. The second group is the really-interesting-new gene/U-box domain-containing (RING) E3 ubiquitin ligases, which can either function as ubiquitin ligases alone or in the form a complex [20]. Both types of E3 ligases play critical roles in plant innate immunity [21]. For example, the Arabidopsis Toxicos en Levadura 9 (ATL9) gene, which encodes a conserved RING-H2 finger protein that has E3 ubiquitin ligase activity, has been shown to play an important role in plant elicitor-mediated signaling [11]. Also, Arabidopsis Toxicos en Levadura 78 (ATL78) has been shown to mediate signaling in drought stress responses [22]. The Arabidopsis Toxicos en Levadura 2 (ATL2) gene family has 
13 members, and all appear to encode conserved RING-Zinc finger proteins with potential E3 ubiquitin ligase activity. They have been shown to be activated by chitin and play important roles in plant defense pathways [22]. The RING-finger domain in ATL2 family members consists of a Cys3HisCys4 amino acid motif, which binds two zinc cations. This protein domain can range from 40 to 60 amino acids in length and is known to be essential for E3 ligase activity [11,22]. All 13 members of the ATL2 family contain both RING domains and transmembrane domains. Four ATL2 members contain PEST domains, which are known to be associated with proteins that have short half-lives within the cell [22]. Our preliminary study has determined that loss-of-function mutations in the atl12 gene led to increased susceptibility to the powdery mildew pathogen Golovinomyces cichoracearum.

In this work, we use the model plant Arabidopsis thaliana to determine the function of ATL12 in chitin elicitor-triggered defense signaling and discover ATL12's mode of activation and regulation. We found that loss of function mutants in atl12 are more susceptible to the powdery mildew infection while overexpression of ATL12 in Arabidopsis increased resistance to mildew infection. Histochemical staining showed that a promoter construct of ATL12 linked to beta-glucoronidase ( $p A T L 12-G U S$ ) was continually expressed in Arabidopsis roots, leaves, stems, and flowers. Subcellular co-localization of the ATL12-GFP fusion protein with the plasma membrane-mcherry marker showed that ATL12 localizes to the plasma membrane. ATL12 is highly induced by chitin at early stages (two hours) after chitin treatment and this expression is linked to MAPK cascade activation. Additionally, the expression of respiratory burst oxidase homolog protein D/F (AtRBOHD/F) is decreased in the atl12 mutant, while the expression of ATL12 is not affected in atrbohd and atrbohf mutants. This suggests that chitin-induced ATL12 expression is also linked to NADPH oxidase AtRBOHD/F-driven ROS production. Furthermore, the expression of ATL12 is upregulated after treatment with salicylic acid (SA) and jasmonic acid (JA), which suggest a possible role for ATL12 in plant hormone-mediated defense responses. Taken together, these results indicate that ATL12 is involved in crosstalk between the SA-, JA-, chitin-induced MAPK and NADPH oxidase-mediated defense responses in Arabidopsis.

\section{Materials and Methods}

\subsection{Biological Materials}

Arabidopsis thaliana ecotype Columbia (Col-0) was used as control in all experiments. T-DNA insertional mutants of atl12: (SALK_201056C (atl12), SALK_066923C (atl12a), SALK_0950303C (at112b)), cerk1 (SALK_007193C, AT3G21630), mapk3 (CS349836, AT3G45640), wrky53 (SALK_034157C, AT4g23810), atrbohd (SALK_083046), and atrbohf (SALK_034668) were obtained from the Arabidopsis Biological Resource Center (ABRC, Ohio State University, Columbus, $\mathrm{OH}, \mathrm{USA}$ ). To screen for homozygous T-DNA mutants, PCR reactions were performed using the following primers:

atl12 (LP 5'-CAATCACCAATCACCTCCAAG-3', RP 5'AATCACAGGATCGTTGTTTCG3), atl12a (LP $5^{\prime}$-GTATTGACCAGTGGCTTGAGC-3' ${ }^{\prime}$ RP 5'-GCAGCTTTAGTGGCGTACATG-3'), atl12b (LP 5'-TAATCTCGCGAATTCATCACC-3', RP 5'- GTCAAGCGACAGATTTTCGTC-3'), cerk1 (LP 5'-CAATTGGTCACTGCAACATTG-3', RP 5' - TTGTACCTGAGGATTGGATCG-3'), wrky53 (LP 5'-TCAGGCACGACTTAGAGAAGC-3' ${ }^{\prime}$ RP 5'-GGGAAAGTTGTGTCAATCTCG3'), mapk3 (LP5'-TCTGCCTTTCCCTCTTCTCTC-3', RP 5'-GACAGCATTGACTCTGGCTCT-3'), atrbohd (LP 5'ATCAGTGCCGCATATTCTTTG-3', RP 5' ATCTTTCTTCCGAAGCACC TC-3'), atrbohf (LP 5'-AAACCAACACGCACCTTATTG-3', RP 5'-ATGAAATTGGCATTGCATTTC-3') and T-DNA insertion border primer LBb1.3: 5' - ATTTTGCCGATTTCGGAAC-3').

The genomic DNA of four-week-old seedlings was extracted using the Cetyltrimethylammonium bromide (CTAB) method. Two paired PCR reactions (FP+RP and LB+RP) and gel electrophoresis were used to screen for ATL2 homozygous lines. All plants were grown in a growth chamber under controlled conditions at $22{ }^{\circ} \mathrm{C}$ day $/ 19^{\circ} \mathrm{C}$ night with $16 \mathrm{~h}$ of light per $24 \mathrm{~h}$ and 50\% humidity. Golovinomyces cichoracearum strain UCSC1 was used as the fungal pathogen and propagated in cucumber. G.cichoracearum was maintained at $22{ }^{\circ} \mathrm{C}$ day $/ 19^{\circ} \mathrm{C}$ night with $16 \mathrm{~h}$ of light per $24 \mathrm{~h}$ and $85 \%$ relative humidity. 


\subsection{Bioinformatics Analysis}

The complete sequences of ATL2 were obtained from GenBank, NCBI, and sequences were compared using the Blastx and Blastn algorithms (http://blast.ncbi.nlm.nih.gov/ Blast.cgi) (ATL12 accessed on 14 April 2019). Open-reading frames (ORFs) of ATL12 were analyzed with ORF Finder (http:/ / www.ncbi.nlm.nih.gov/gorf/orFig.cgi) (accessed on 14 April 2019), and its gene structure and functional domains were predicted with Uniprot (https:/ / www.uniprot.org) (accessed on 14 April 2019) and Smart (http:/ / smart.emblheidelberg.de/) (accessed on 14 April 2019). The amino acid sequences and functional domains of ATL2 were identified with Blastp (http://blast.ncbi.nlm.nih.gov/Blast.cgi) (accessed on 14 April 2019). Sequence alignments were made using T-coffee (http:// tcoffee.crg.cat/apps/tcoffee/do:regular) (accessed on 14 April 2019) and Boxshade (http: //www.ch.embnet.org/software/BOX_form.html) (accessed on 14 April 2019). Tools used for general bioinformatics analysis and protein-specific domains can be found at: http: / /www.ncbi.nlm.nih.gov / (accessed on 14 April 2019) and http:/ / www.ebi.ac.uk/Tools/ (accessed on 14 April 2019).

\subsection{Generation of Transgenic Plants and Constructs}

To generate constructs for production of transgenic plants in this study, the ATL12 sequence was amplified using Phusion ${ }^{\circledR}$ High-Fidelity DNA Polymerase from New England Bio-Labs (NEB, Ipswich, MA, USA). For Gateway entry cloning, Taq DNA polymerase was added to the raw PCR product to generate $3^{\prime}$ A-Overhangs. The resulting PCR products were purified, and entry clones were generated by recombination into the $\mathrm{pCR}^{\mathrm{TM}} 8 / \mathrm{GW} / \mathrm{TOPO}$ vector (Thermo Fisher Scientific, Waltham, MA, USA), using the $\mathrm{pCR}^{\mathrm{TM}} 8 / \mathrm{GW} / \mathrm{TOPO}^{\circledR} \mathrm{TA}^{\mathrm{T}}$ Cloning ${ }^{\circledR}$ Kit (Thermo Fisher Scientific, Waltham, MA, USA). To generate overexpression constructs for ATL12, we utilized the destination vector pMDC 32(35S promoter-attR1-CmR-ccdB-attR2). After sequencing to confirm that the clone is in frame and oriented correctly, the recombinant construct was transformed into Agrobacterium tumefaciens strain (pGV3101) via chemical transformation using the floral dip method. The positive transformants with green expanded cotyledons and long hypocotyls were selected in $50 \mu \mathrm{g} \mathrm{mL}{ }^{-1}$ hygromycin MS agar plates for 7 to 10 days. The T3 progeny from these transformants was used in this study. Transcript levels of ATL12 were measured via quantitative RT-PCR in all over-expression lines to confirm results.

\subsection{Subcellular Localization of ATL12 Protein}

ATL12:GFP overexpression transgenic plants were constructed expressing an Nterminal ATL12-GFP fusion protein. For the ATL12:GFP transgenic plants, the ATL12 sequence was amplified using Phusion ${ }^{\circledR}$ High-Fidelity DNA Polymerase (New England Bio-labs). Entry clones were generated by recombination into the $\mathrm{pCR}^{\mathrm{TM}} 8 / \mathrm{GW} / \mathrm{TOPO}$ vector, based on a previously published protocol [11]. The destination vector $\mathrm{pMDC}$ 43(35S-attR1-CmR-ccdB-attR2-GFP) was used to generate overexpression constructs. The construct sequence was confirmed, and then the recombinant construct was transformed into Agrobacterium tumefaciens strain (pGV3101). For subcellular localization in tobacco cells using confocal fluorescent microscopy, ATL12:GFP and the fluorescence plasma membrane marker pm-rk (plasma membrane marker fused with red ${ }^{\mathrm{M}}$ cherry protein) were co-infiltrated into tobacco cells, the tobacco was then placed in the dark for two days for the fusion protein to be expressed and then the leaves were examined.

PCR-driven overlap extension was used to delete the transmembrane domain of ATL12 to construct ATL12 $\triangle T M$, and three-step fusion PCR was conducted to create the 35S:ATL12 $\triangle T M$ : GFP construct.

First step primers:

pATL12-ATL12 $\triangle \mathrm{TM}$ :

5'-ATCCACCTTCATAAGCTGGTAATAGA-3' (pATL12-ATL12 forward)

$5^{\prime}$-AGGTGAGAGTTCCGGTGATGATA-3' (ATL12 $\triangle T M 1$ reverse)

Second step primers: 
5'-ATCACCGGAACTCTCACCTTTG-3' (ATL12 $\triangle T M 2$ forward)

5'-TGTTTTAGGATGGTGATTCGATGAG-3' (pATL12-ATL12 reverse)

Third step primers:

pATL12-ATL12 $\triangle T M: 5^{\prime}$-ATCCACCTTCATAAGCTGGTAATAGA-3' (pATL12-ATL12 forward) and 5'-TGTTTTAGGATGGTGATTCGATGAG-3' (pATL12-ATL12 reverse)

The resulting PCR products were gel purified and cloned into a TOPO entry vector based on previous protocols [11]. Positive clones were recombined with pMDC32 (CD3-738) using LR Clonase Enzyme Mix and then transformed into A. tumefaciens strain GV3101.

35S:ATL12 $\triangle T M: G F P$ agrobacterium GV3101 strain and fluorescence plasma membrane marker pm-rk (plasma membrane marker fused with red ${ }^{\mathrm{M}}$ cherry protein) were co-transferred into tobacco cells. Free GFP was also infiltrated into tobacco leaves as a control. Fluorophores are visualized concurrently using a Nikon ECLIPSE Ti2 confocal fluorescent microscope (Nikon, Tokyo, Japan) equipped with an OptiGrid imaging system using FITC HYQ (Excitation: 460-500 nm; Emission: 510-560 nm) and TRITC HYQ (Excitation: 530-560 nm; Emssion: 590-650 nm) filters (Nikon, Tokyo, Japan). Images were generated and merged using NIS-Elements software Ver4.60.00 (Nikon, Tokyo, Japan).

\subsection{Disease Assessment}

To assess the susceptibility of Arabidopsis ATL12 mutants to pathogen infection, the following experiments were performed. Arabidopsis seeds were placed in the cold room for three days, planted in soil, and then transferred to a growth chamber $\left(22^{\circ} \mathrm{C}\right.$ day $/ 19{ }^{\circ} \mathrm{C}$ night with $12 \mathrm{~h}$ of light per $24 \mathrm{~h}$ and $50 \%$ relative humidity). 21-day old seedlings were inoculated with powdery mildew and placed in the infection chamber with the same temperature and light conditions, except at $80 \%$ humidity. To qualitatively assess how the disease develops, we observed the appearance of inoculated leaves 7 days post-inoculation to check powdery mildew infection symptoms via trypan blue staining. Inoculated leaves were treated with ethanol before staining with trypan blue solution for $15 \mathrm{~min}$. Leaves were harvested for staining at 6- or 7-days post-inoculation. Also, the number of spores per colony was determined to quantitatively assess the susceptibility of the mutants to pathogen infection. Approximately $0.5 \mathrm{~g}$ of seedlings were harvested at $7 \mathrm{dpi} .5 \mathrm{~mL} \mathrm{H}_{2} \mathrm{O}$ was then added, and spores were released by vortexing for $30 \mathrm{~s}$ at maximum speed. For each sample, spore suspension solutions were filtered and added onto the eight $1 \mathrm{~mm}^{2}$ fields of a Neubauer-improved haemocytometer and spores were counted. Spore counts results were averaged and then normalized to the weight of seedlings. Each experiment was repeated 3 times. Statistical significance among samples was analyzed using one-way ANOVA followed by post hoc tests.

\subsection{Histochemical Staining Assay}

Transgenic Arabidopsis plants expressing pATL12-GUS were generated and a histochemical staining assay was used to determine the pATL12-GUS ( $\beta$-Glucuronidase) expression pattern. ATL12 sequence was amplified using Phusion ${ }^{\circledR}$ High-Fidelity DNA Polymerase from New England Bio-Labs. Taq DNA polymerase was added to the raw PCR product to generate $3^{\prime}$ A-overhangs and the resulting PCR products were purified, and entry clones were generated by recombination into the $\mathrm{pCR}^{\mathrm{TM}} 8 / \mathrm{GW} / \mathrm{TOPO}$ vector. To generate the overexpression constructs for ATL12, we utilized the destination vector pMDC 162 (-attR1-CmR-ccdB-attR2-GUS). Then the recombinant construct was transformed into Agrobacterium tumefaciens strain (pGV3101) using chemical transformation. The positive clones were selected in LB agar plates contained $100 \mu \mathrm{g} \mathrm{mL} \mathrm{m}^{-1}$ kanamycin and the frame and orientation were checked via sequencing. The floral dip method [23] was then used to generate overexpression transgenic plants and selection for the transgenics was performed using $1 \times$ MS agar plates contained $50 \mu \mathrm{g} \mathrm{mL}^{-1}$ hygromycin. The positive transformants with green expanded cotyledons and long hypocotyls were selected in hygromycin agar plates for 7 to 10 days. The T3 progeny from these transformants were used in this study. The screened pATL12-GUS seeds were placed into $1 \times$ MS liquid culture and grown to 
specific developmental stages. The seedlings and tissues were then collected and stained overnight at $37^{\circ} \mathrm{C}$ in GUS staining buffer. GUS expression was observed directly under a dissecting microscope.

\subsection{Reactive Oxygen Species (ROS) Detection via DAB Staining Assay}

To determine if $A T L 12$ expression was related to ROS production during pathogen infection, Arabidopsis Col-0, the T-DNA insertional mutants of ATL12 and ATL12 overexpression lines were grown under normal conditions $\left(22^{\circ} \mathrm{C}\right.$ day $/ 19^{\circ} \mathrm{C}$ night with $12 \mathrm{~h}$ of light per $24 \mathrm{~h}$ and $50 \%$ relative humidity) for 3 weeks. Plants were then inoculated with powdery mildew and placed in a growth chamber with the same temperature and light conditions, except at $80 \%$ humidity. At 7 days post-inoculation, at least 5 leaves were removed from each plant and placed in a 24-well microtiter plate. $1 \mathrm{~mL}$ of the $10 \mathrm{mM} \mathrm{Na}_{2} \mathrm{HPO}_{4}$ DAB staining solution ( $50 \mathrm{mg} \mathrm{DAB}, 45 \mathrm{~mL}$ sterile $\mathrm{H}_{2} \mathrm{O}, 25 \mu \mathrm{L}$ Tween $20(0.05 \% v / v)$ and $2.5 \mathrm{~mL} 200 \mathrm{mM} \mathrm{Na}_{2} \mathrm{HPO}_{4}, \mathrm{pH}$ 3.0) was added to the leaf or leaves. The volume in each well was adjusted to ensure that the leaves were immersed in the DAB solution. The brown precipitate formed by the $\mathrm{DAB}$ reacting with the hydrogen peroxide was observed by light microscopy, and photographs were taken using an imaging system.

\subsection{Quantitative RT-PCR and RT-PCR}

To determine the temporal expression patterns of ATL12, we performed qRT-PCR with chitin-treated seedlings. Arabidopsis seedlings were growing in MS liquid medium in $50 \mathrm{~mL}$ Falcon tube for 14 days. We immersed the 14-day old wild type Arabidopsis seedlings with MS liquid medium contained $100 \mathrm{mg} / \mathrm{mL}$ chitin and then collected tissues at several time points. ( $1 \mathrm{~h}, 2 \mathrm{~h}, 4 \mathrm{~h}, 8 \mathrm{~h}, 16 \mathrm{~h}, 24 \mathrm{~h})$. To determine if expression levels of ATL12 were regulated by the classical plant defense pathways mediated by salicylic and jasmonic acids, we treated wild-type Arabidopsis seedlings with water, chitin, salicylic acid (SA) $(2 \mathrm{mM})$, or jasmonic acid (JA) $(100 \mu \mathrm{M})$ for two hours. The seedlings from the different treatments were then collected, frozen in liquid nitrogen and stored at -80 for qRT-PCR analysis. Total RNA was isolated from frozen tissues using TRizol Reagent (Invitrogen ${ }^{\circledR}$, Carlsbad, CA, USA) according to the manufacturer's protocol. RNA samples were treated with RQ1 DNase (Promega, Madison, WI, USA). Trace amounts of genomic DNA were removed by digestion with the Turbo DNA-free ${ }^{\mathrm{TM}}$ system (Ambion, Austin, TX, USA). First-strand cDNA synthesis was primed with an oligo (dT)15 anchor primer and cDNA was synthesized using a First-Strand Synthesis Kit (Amersham-Pharmacia, Rainham, UK) according to the manufacturer's protocol. An aliquot of $1.5 \mu \mathrm{L}$ of the firststrand synthesis reaction was used as a template for PCR amplification. To ensure that the sequence amplified was specific, a nested PCR was performed using $1 \mu \mathrm{L}$ of a 1:50 dilution of the products synthesized in the first PCR reaction as a template. The RT-PCR, PCR, and nested PCR program consisted of: $3 \mathrm{~min}$ at $96^{\circ} \mathrm{C}, 30$ cycles of $30 \mathrm{~s}$ at $94{ }^{\circ} \mathrm{C}, 30 \mathrm{~s}$ at $65^{\circ} \mathrm{C}$, and $1 \mathrm{~min}$ at $72{ }^{\circ} \mathrm{C}$, and a final extension step of $7 \mathrm{~min}$ at $72{ }^{\circ} \mathrm{C}$. Amplified PCR fragments were visualized using $1 \%$ agarose gels.

The following gene-specific primers are used for RT-PCR:

ATL12 (At2g20030): 5-CCCAACACACAGAGAGGTCGTC-9 (forward) and 5-GCTTCC ACAATGACCTCCGA-9 (reverse);

MAPK3 (At3g45640) 5' -TCTGCCTTTCCCTCTTCTCTC-3' (forward primer), and 5' GACAGCATTGACTCTGGCTCT-3' (reverse primer);

AtRBOHD (At5G47910) 5'ATCAGTGCCGCATATTCTTTG-3' (forward primer), and $5^{\prime}$-ATC

TTTCTTCCGAAGCACC TC-3' (reverse primer);

AtRBOHF (At1G64060) 5'-AAACCAACACGCACCTTATTG-3' (forward primer), and 5'-ATGAAATTGGCATTGCATTTC-3' (reverse primer);

ACTIN-2 (At3g18780): 5-AGCAGCTTCCATTCCCACAA -3 (forward) and 5- CATGCCATCCTCCGTCTTGA -3 (reverse). 
Quantitative RT-PCR experiments were performed using a SYBR ${ }^{\circledR}$ Green qPCR kit (Finnzymes, Espoo, Finland) with reactions at a final volume of $20 \mu \mathrm{L}$ per well and using the cycle protocol recommended by the manufacturer. Samples were run in a DNA Engine Opticon ${ }^{\circledR} 2$ System instrument with PTC-200 DNA Engine Cycler and CFD-3220 Opticon ${ }^{\mathrm{TM}}$ 2 Detector (BioRad, Hercules, CA, USA). Gene-specific primers were designed using the Primer Express 2.0 program (Applied Biosystems, Foster City, CA, USA) and minimal self-hybridization and dimer formation of primers was determined using the Oligo 6.0 program (Molecular Biology Insights, West Cascade, CO, USA). Primers with annealing temperatures of $62{ }^{\circ} \mathrm{C}$ to $65^{\circ} \mathrm{C}$ that amplified products with lengths of about $300 \mathrm{bp}$ were selected and then verified for specificity by BLAST searches. The efficiency of amplification for each gene was calculated as recommended by the manufacturer (BioRad, Hercules, CA, USA).

The following gene-specific primers were used:

ATL12 (At2g20030): 5-GAATTATGCCGTTACTGCGACC-9 (forward) and 5-ATTTTGGCGTGTCGTGTTTAGG -9 (reverse);

PR1 (At2g14610): 5-GCCTTCTCGCTAACCCACAT-3 (forward) and 5-CGGAGCTACGCAGAACAACT-3 (reverse);

MAPK3 (At3g45640): 5-TCATCATTCGGGTCGTGCAA-3 (forward) and 5-ACTTCCCAACTTCCCACGTC-3 (reverse); PDF1.2 (At5g44420):5-TGTTCTCTTTGCTGCTTTCGAC -3 (forward) and 5-TGCTGGGAAGACATAGTTGCAT -3 (reverse); CERK1 (At3g21630) 5'-TCGAAACAGTTCTTGGCGGA-3' (forward) and 5'-GGTTCTCGTCCTGACCCATG-3' (reverse); NPR1 (At1g64280) 5'-CCGGACCTGATGTATCTGCTC-3' (forward) and 5'-GCGGTGTTGTTGGAGTCTTTC-3' (reverse);

JAZ1 (At1g19180): 5-GAGCAAAGGCACCGCTAATA-3 (forward) and 5-TGCGATAGTAGCGATGTTGC-3 (reverse);

WRKY53 (At4g23810) 5'-TGGTGTCTTGTCGCTTCTCC-3' (forward) and 5'-CAGAGATCAGACGGGGATGC-3' (reverse);

Beta-ACTIN (At3g18780): 5-AGCAGCTTCCATTCCCACAA -3 (forward) and 5- CATGCCATCCTCCGTCTTGA -3 (reverse).

Relative fold changes in transcript levels were determined using the double delta $\mathrm{Ct}$ Value $(\Delta \Delta \mathrm{Ct})$ method. Data were acquired and analyzed using ANOVA followed by Turkey post hoc analysis. Three independent biological replicates were used in each experiment.

\section{Results}

\subsection{Sequence Analysis of the Arabidopsis thaliana ATL12 Gene}

In order to identify the ATL12 gene, information was analyzed from two publicly available databases, the National Center for Biotechnology Information (NCBI) database, and The Arabidopsis Information Resource (TAIR) database. ARABIDOPSIS TOXICOS EN LEVADURA 12 (ATL12), also named At2g20030 or ATL2D, belongs to the ATL2 gene family, a group of really conserved C3HC4 RING-type protein with putative E3 ubiquitin ligase activity. The ATL12 gene contains one exon and no introns, and the complete cDNA is $1505 \mathrm{bp}$ long with its predicted ORF (1173 bp) encoding a 390 amino acid protein with a signal peptide, a transmembrane domain, and a RING-finger domain, as shown in Figure 1A. The complete cDNA and amino acid sequences of the ATL12 are shown in Supplement Figure S1. The Arabidopsis Toxicos en Levadura 2 (ATL2) gene family has 13 members and all appear to encode conserved RING-Zinc finger proteins with potential E3 ubiquitin ligase activity. They have been shown to be activated by chitin elicitors and play important roles in plant defense pathways [22]. All 13 members of the ATL2 family contain RING domains and transmembrane domains, with only four members that have PEST domains. PEST domains are known to be associated with proteins that have short half-lives within the cell. Alignment of the ATL12 RING Zinc-finger domain amino acid sequence with the other ATL2 gene family members showed that the consensus sequence 
for this group of RING proteins is: C-X2-CL-X-E-X7-R-X2-P-X-C-X-H-X-FH-X2-C-X-D-X$\mathrm{W}-\mathrm{X} 6-\mathrm{CP}-\mathrm{X}-\mathrm{C}$, where $\mathrm{X}$ is any amino acid, as shown in Figure $1 \mathrm{~B}$.

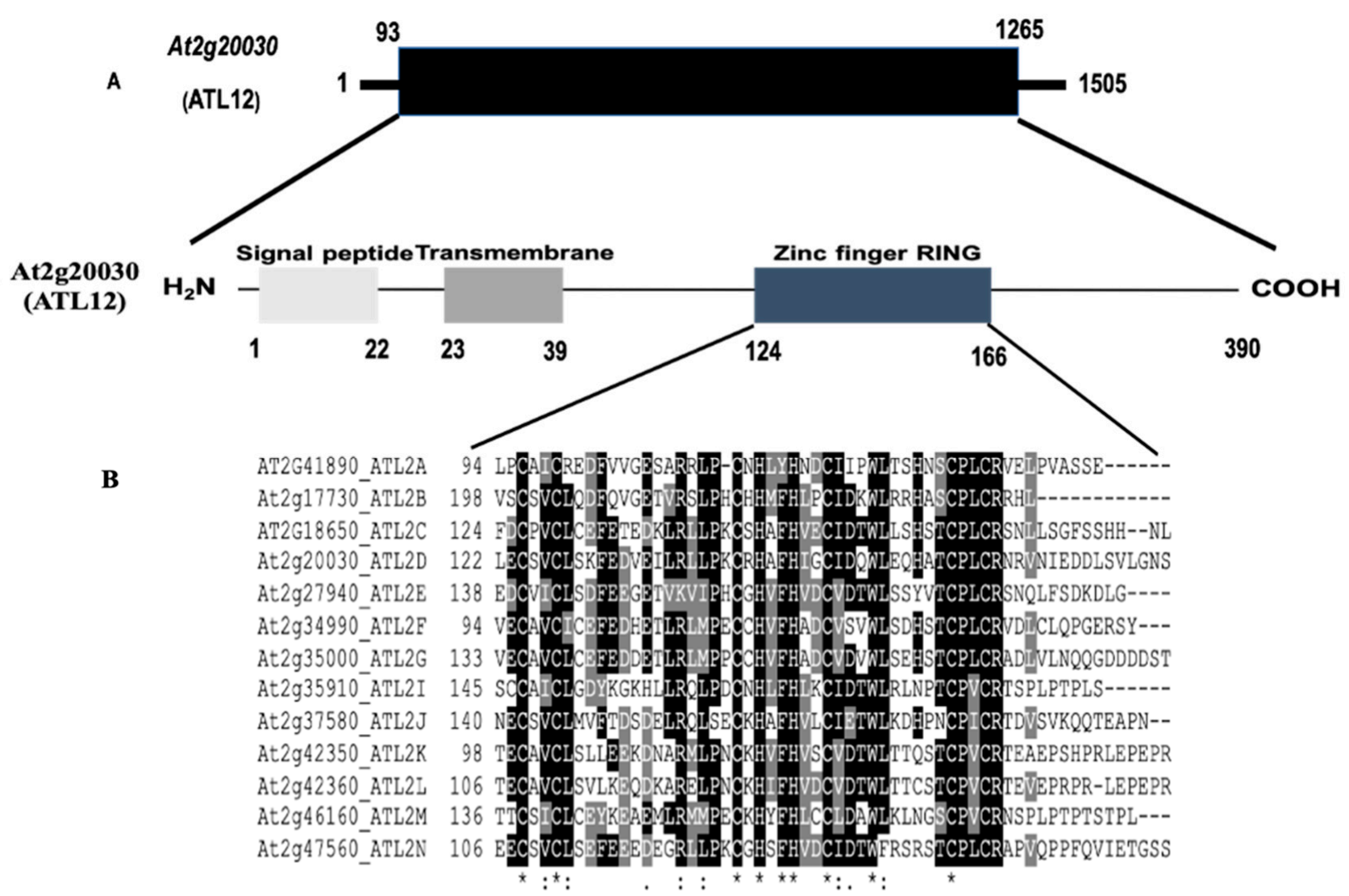

Figure 1. Sequence and domain analysis of ATL12. (A) The structure of genes and predicted domains for ATL12. One transmembrane domain (TM); and a C3HC4 RING Zinc-finger domain. (B). The consensus sequence for this group of RING zinc-fingers is C-X2-CL-X-E-X7-R-X2-P-X-C-X-H-X-FH-X2-C-X-D-X-W-X6-CP-X-C, where X is any amino acid. * indicates perfect alignment; : indicates a site exhibiting strong similarity; . indicates a site exhibiting weak similarity.

\subsection{Tissue Expression Pattern of ATL12}

To investigate where and when ATL12 is expressed at the tissue level, we generated transgenic Arabidopsis plants expressing the native promoter of ATL12 driving a beta-glucaronidase (GUS) fusion in transgenic plants (pATL12-GUS) and performed a histochemical staining assay to determine the ATL12 expression pattern. Twenty of the screened T3 pATL12-GUS seeds were placed into 1x MS liquid culture and grown to specific developmental stages ( 2 days, 3 days, 4 days, 5 days, 1 week, 2 weeks, 3 weeks, and 1 month). The results of this study are shown in Figure 2. The results showed that ATL12 express at germinating seed and cotyledons during early embryogenesis (Figure 2a,b) and the root, leaf and stem of growing seedlings (Figure 2c-i). In addition, ATL12 is also found to express in flowers (Figure 2k,l).

\subsection{ATL12 Localizes to the Plasma Membrane}

Since ATL12 contains a transmembrane domain, we wanted to determine the subcellular localization of ATL12. To do this, a construct was made containing a C-terminal fusion of the green fluorescent protein (GFP) to the ATL12 gene under the control of CaMV 35S promoter. 35S-ATL12-GFP and the plasma membrane organelle fluorescence marker PM-rk were co-infiltrated into Nicotiana benthamiana (tobacco) leaf cells, and the tobacco leaves were placed in the dark for two days. The GFP and rk Fluorophores were then visualized in the leaf cells concurrently using confocal fluorescent microscopy. When visualized, the 
35S-ATL12-GFP construct co-localized with the PM-rk marker PIP2 in the tobacco cells. This confirmed its localization to the plasma membrane as shown in Figure 3, top row. Additionally, a 35S-GFP construct was used as a negative control for GFP localization to the nucleus and cytosol (Figure 3, bottom row). Fluorescence was detectable within the nucleus in the tobacco cells expressing the 35S-GFP construct and the GFP signal could be seen in the nucleus (Figure 3, bottom row, white arrow). To determine if the transmembrane domain of ATL12 is responsible for its localization at the plasma membrane, an ATL12- $\triangle$ TM-GFP construct lacking the transmembrane domain was made and infiltrated into tobacco leaves. The ATL12- $\triangle$ TM-GFP protein was observed in the cytosol and in the nucleus (Figure 3, middle row, white arrow) but not at the plasma membrane, suggesting that the transmembrane domain of ATL12 is necessary for its localization at the plasma membrane.

a
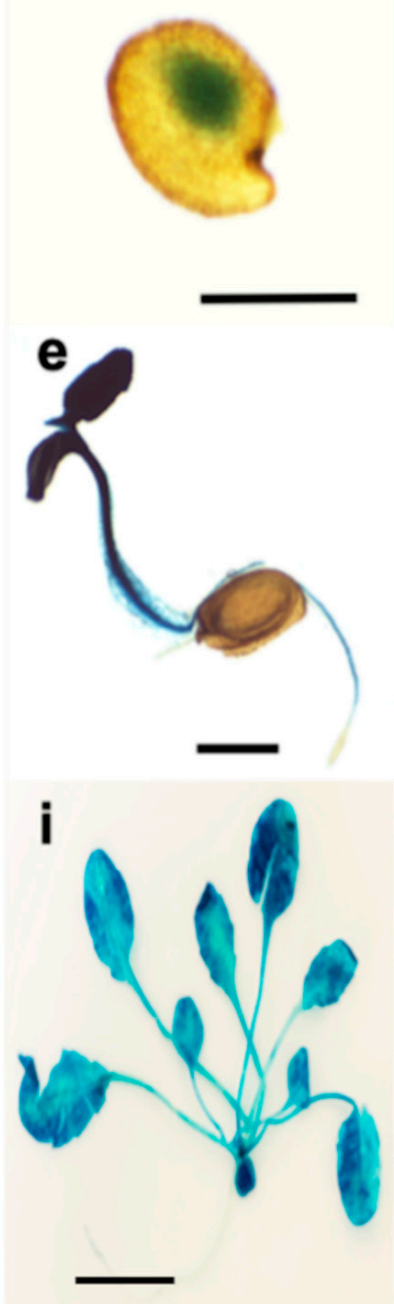

b
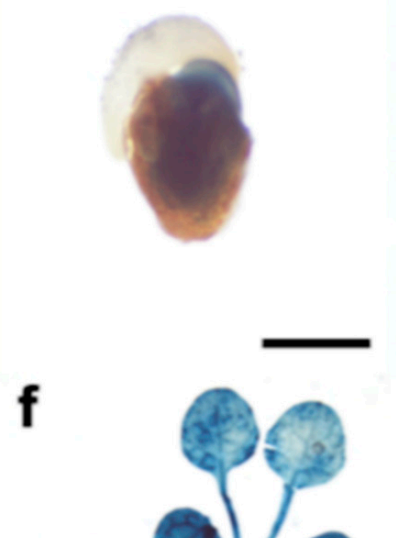
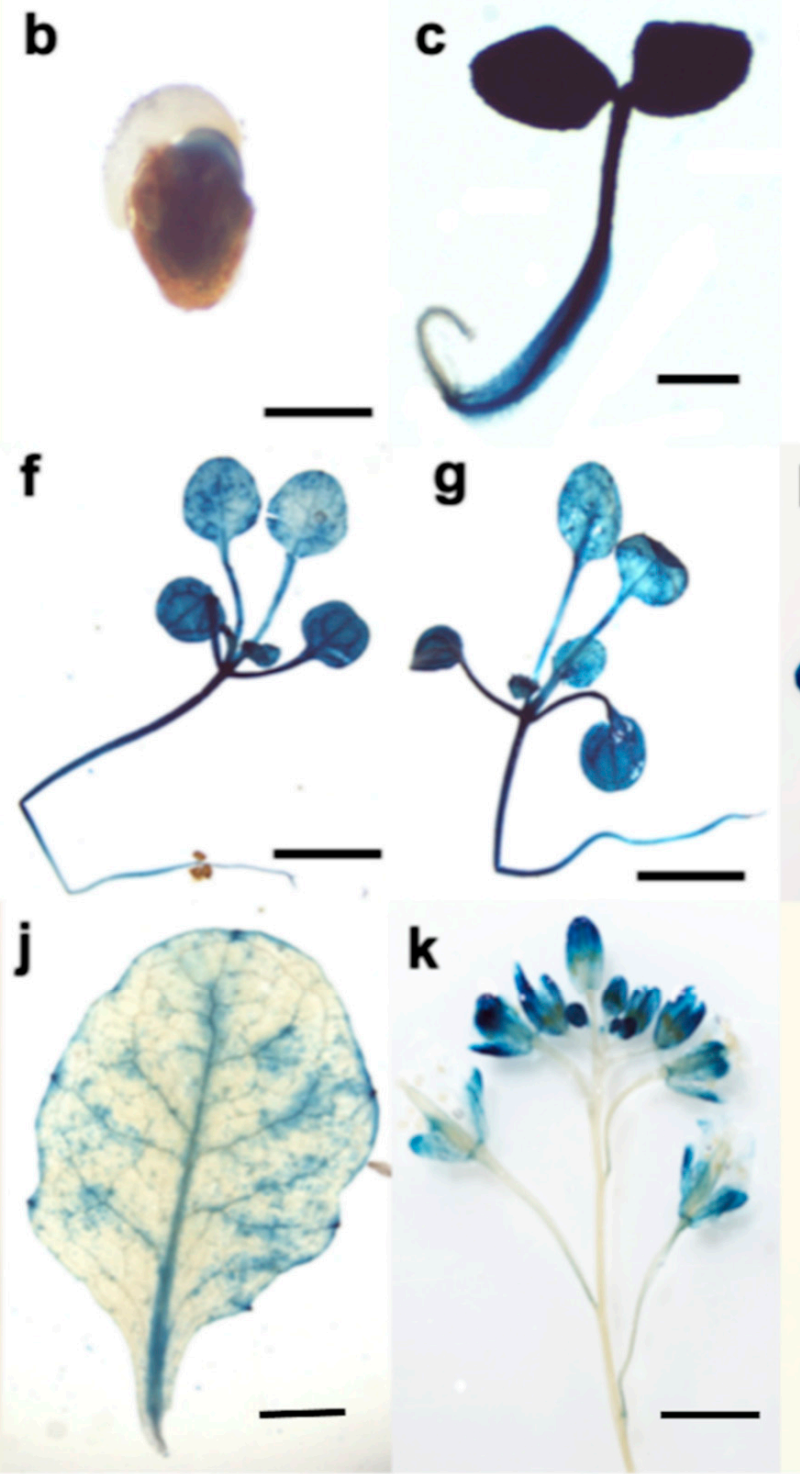
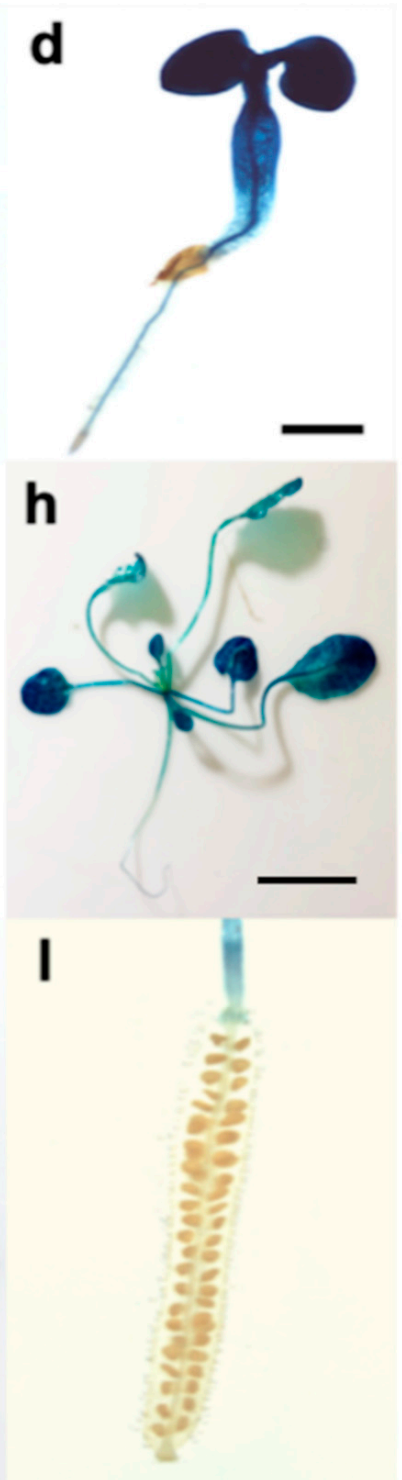

Figure 2. Tissue expression pattern of ATL12. Histochemical analysis of ATL12 native promoter activity in different Arabidopsis tissues. pATL12-GUS activity was detected in 1-day-old germinating seeds, (a) 2-day-old seedlings (b), 3day-old seedlings (c), 4-day-old seedlings (d), 5-day-old seedlings (e), 6-day-old seedlings (f), one week-old seedlings (g), two-week-old seedlings (h), three-week-old seedlings (i), four-week-old leaf (j), Flowers (k), and siliques (1). Scale bar represents $1 \mathrm{~mm}$. 


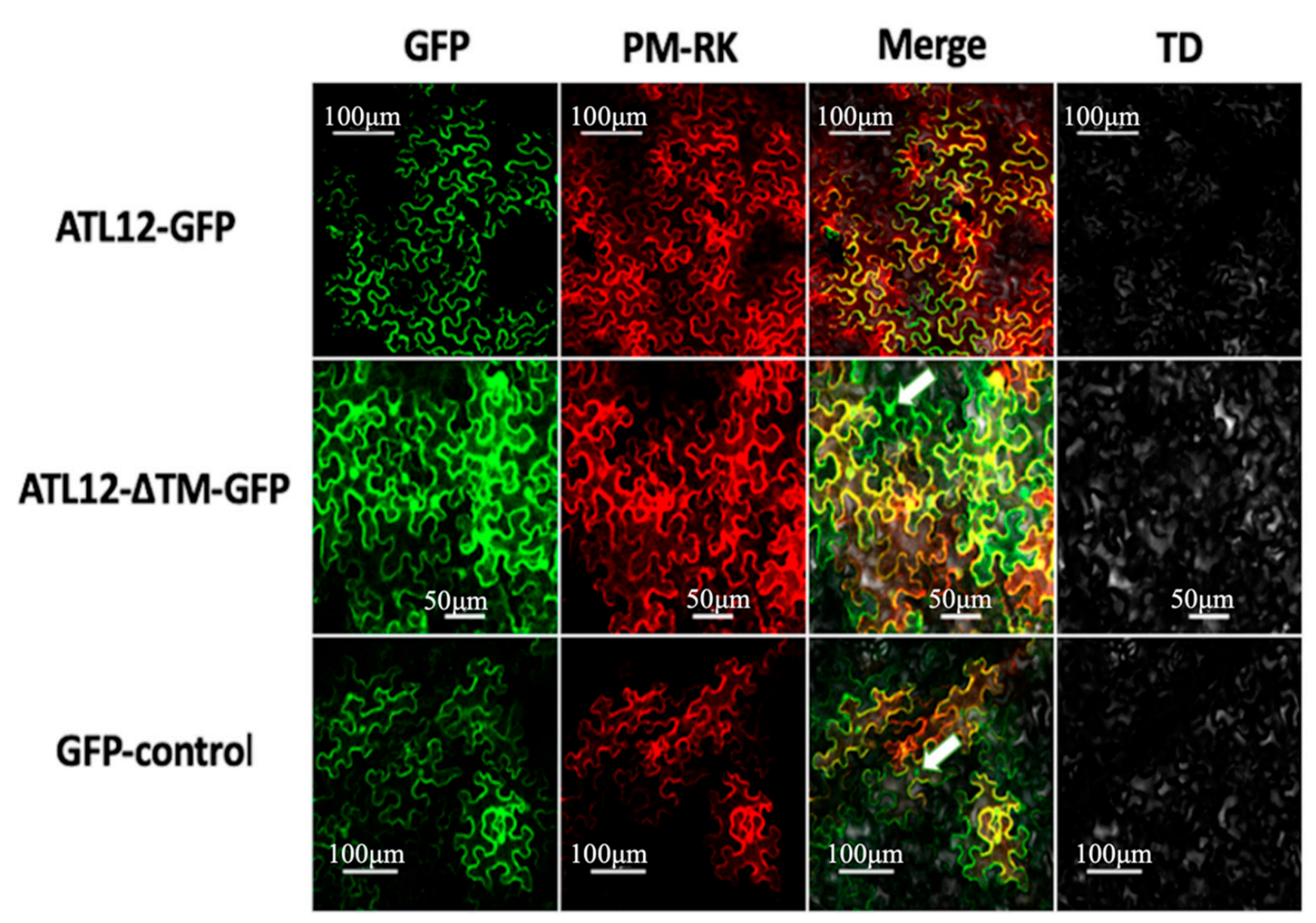

Figure 3. ATL12 protein is localized to plant plasma membrane. Sub-cellular localization of the ATL12-GFP protein. GFP and plasma membrane-M $\mathrm{M}^{\text {cherry }}$ marker (PM-RK) were used as specificity controls for cytosol proteins PM-localized proteins. FITC HYQ channel (Excitation: 460-500 nm; Emission: 510-560 nm) was used to detect GFP signal and TRITC HYQ (Excitation: 530-560 nm; Emission: 590-650 nm) filters were used for PM-RK signal.

\subsection{ATL12 Expression Is Induced by Chitin Treatment}

To determine the expression pattern of ATL12 after the chitin treatment we used histochemical staining of transgenic plants containing the ATL12 nature promoter fused with GUS. Four-week old transgenic leaves, expressing pATL12-GUS were immersed in $1 \mathrm{mg} / \mathrm{mL}$ crab shell chitin (CSC) for chitin treatment. Distilled water was used as a control. As shown in Figure 4A, ATL12 expression is highly induced after treatment with chitin for $2 \mathrm{~h}$ compared with the water control. To further determine the timing of ATL12 expression after chitin treatment, two week old Col-0 wild type Arabidopsis were treated with $100 \mathrm{mg} / \mathrm{mL}$ chitin at different time points and the expression levels of ATL12, the defense marker gene MITOGEN-ACTIVATED PROTEIN KINASE 3 (AtMAPK3) and the reference gene beta-actin were determined using qRT-PCR. Wild-type Col-0 plants were treated with $100 \mathrm{mg} / \mathrm{mL}$ chitin and tissue samples were harvested at four early time points: $1 \mathrm{~h}, 2 \mathrm{~h}, 4 \mathrm{~h}$, and $8 \mathrm{~h}$ post-treatment and at two late infection time points; $16 \mathrm{~h}$ and $24 \mathrm{~h}$. The result of qRT-PCR is shown in Figure 4B. MAPK3 expression is highly induced at the very early time point and is continuously induced all the time. ATL12 is highly induced by chitin treatment and at the very early time point $(2 \mathrm{~h})$, then expression started to drop at $4 \mathrm{~h}$ and quickly drops off to normal levels at $16 \mathrm{~h}$, which suggested that ATL12 is involved with chitin elicitor triggered immune response. 
A

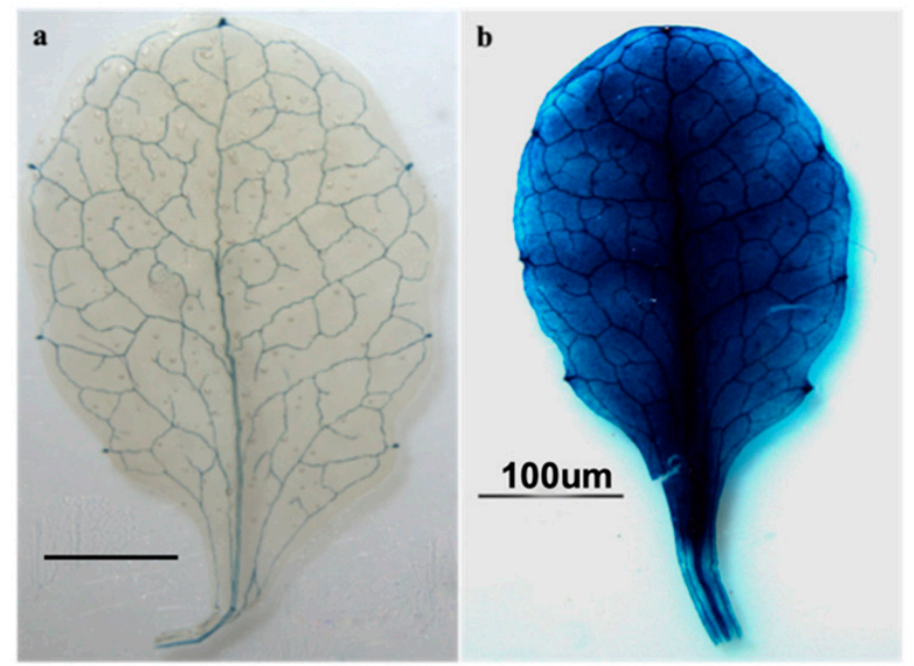

B

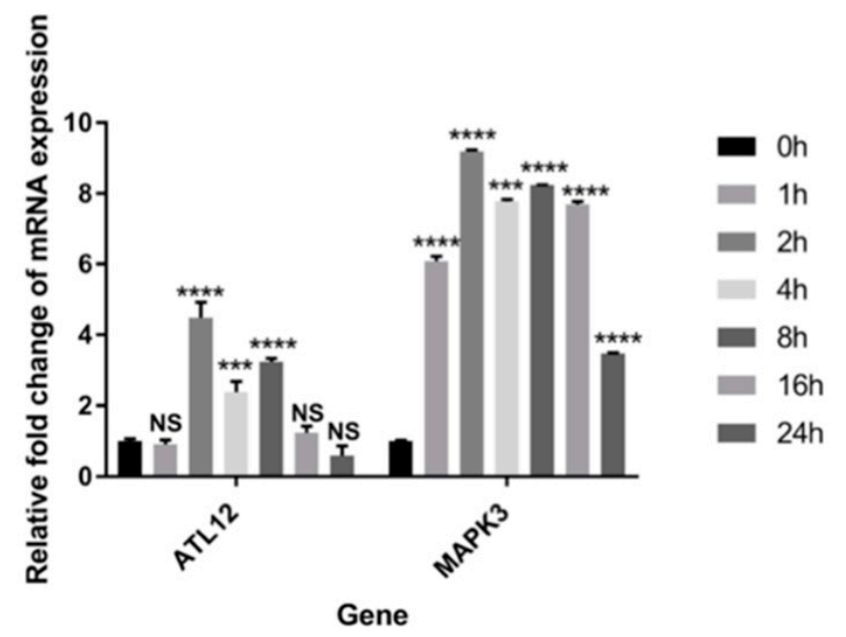

Figure 4. Expression pattern of ATL12 after chitin treatment. (A): Histochemical staining assay of pATL12-GUS. 4 weeks old transgenic plant leaves express pATL12-GUS in leaves were treated with water (a) or with (b) $1 \mathrm{mg} / \mathrm{mL}$ CSC treatment for $2 \mathrm{~h}$, and then subject to GUS staining. (B). qRT-PCR analysis of ATL12 mRNA and MAPK3 expression in response to chitin at different time points. Asterisks indicate statistically significant differences between the samples treated and untreated, according to the One-way ANOVA analysis and multiple comparison post-Tukey's test. The experiments were repeated three times. ${ }^{* * *}$ indicates $p<0.0001,{ }^{* * *}$ indicates $p<0.001$, and NS indicates not significant. The black scale bar indicates $100 \mathrm{um}$.

\subsection{Mutants of atl12 Are More Susceptible to Golovinomyces Cichoracearum Infection}

To determine if ATL12 plays a role in Arabidopsis defense against powdery mildew infection, we obtained three T-DNA insertion mutant lines of atl12 from the Arabidopsis Biological Resource Center (ABRC, Ohio State University) with stock numbers SALK_201056C SALK_066923C, and SALK_0950303C. The T-DNA insertion position of the three mutants and the confirmation of all three homozygous T-DNA insertion mutant lines were shown in Supplementary Materials Figure S2. Three T-DNA insertional mutants lines (atl12, atl12a, and atl12b), Col-0 wild type, and NahG (a hyper-susceptible mutant) were planted and 21-day old seedlings were inoculated with powdery mildew. To assess how the disease develops, we observed the appearance of inoculated leaves 7 days post-inoculation and determined the extent of powdery mildew infection symptoms via trypan blue staining as shown in Figure 5A,B. After powdery mildew infection, the atl12 mutants' appearance showed more powdery mildew development and spread compared to Col-0. While the 
overexpression line of ATL12 showed little to no development and growth of the powdery mildew pathogen across the leaf surface (Figure 5A,B). In addition, the number of spores per colony was determined to quantitatively assess the susceptibility of the mutants to pathogen infection. Compared to Col-0 wild type, T-DNA insertional mutants of atl12, atl12a, and atl12b all displayed higher levels of spore generation. To further confirm ATL12's role in fungal defense, we generated ATL12 over-expression transgenic line, 20-30 seeds of the $\mathrm{T} 3$ progeny from transformants were used in the disease assessment assay. As shown in Figure 5C, we noticed that overexpression of ATL12 has fewer spores generated in response to fungal infection compared to Col- $0 \mathrm{WT}$, which suggests that over-expression of ATL12 increases the resistance of Arabidopsis to fungal infection. Taken together, these results indicate that ATL12 has a positive correlation with resistance to powdery mildew infection.

A
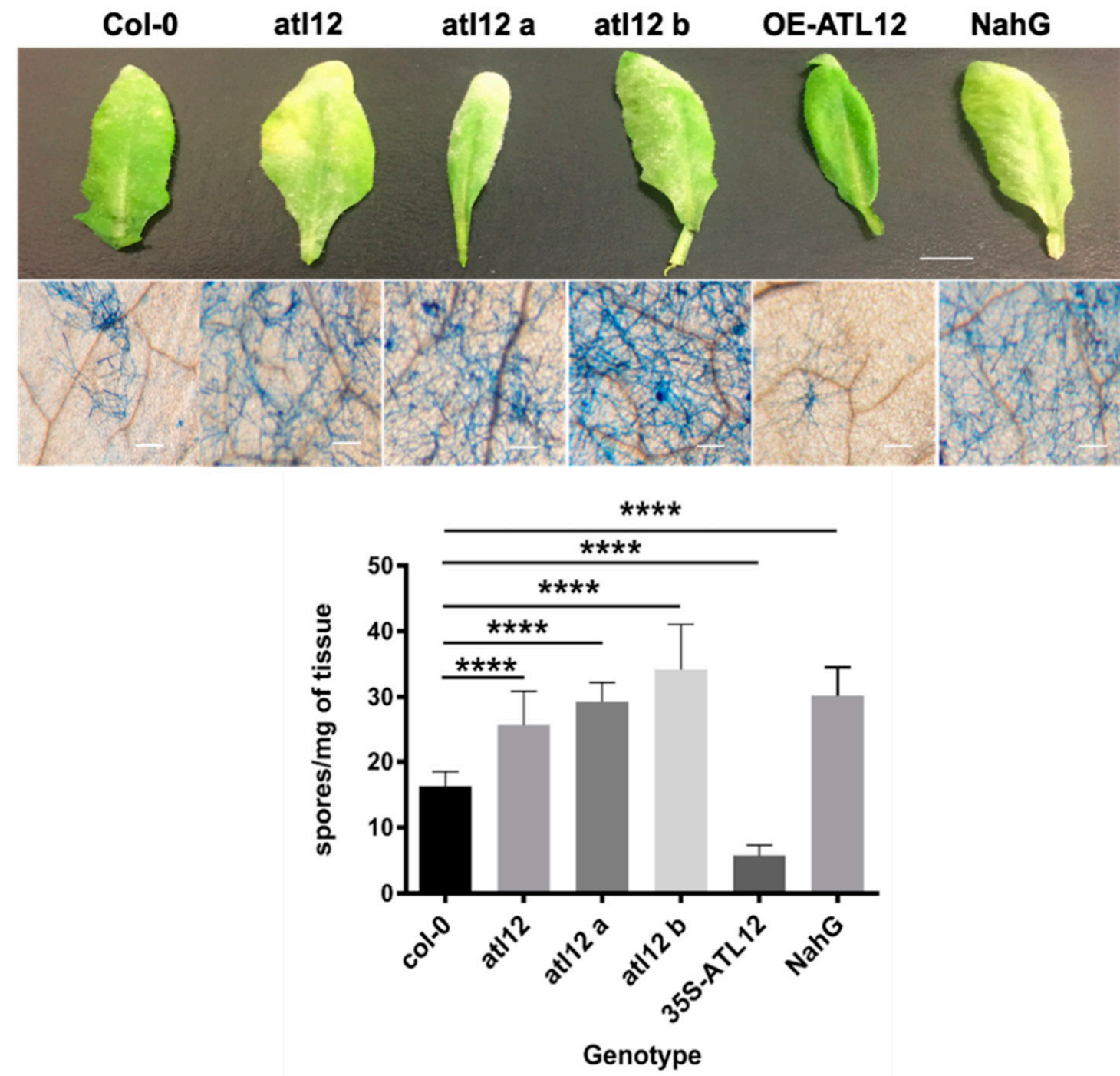

Figure 5. Phenotypic analysis of Col-0 wild-type (WT), atl12 mutants and overexpression (OE) 35S:ATL12 plants in response to powdery mildew infection. (A). Leaf appearance of wildtype, atl12 mutants, overexpression (35S:ATL12) seedlings and NahG transgenic plants (highly susceptible to fungal infection) 7d after powdery mildew infection. The white scale bar indicates $1 \mathrm{~mm}$. (B). Trypan blue staining of the fungal structures on leaves 7days after fungal infection. (C). Quantitative phenotypic analysis of each seedling. One-way ANOVA followed by Tukey's test was used to analyze the differences among treatments. Experiments were repeated three times. ${ }^{* * * *}$ indicates $p<0.0001$. 
3.6. Chitin-Induced ATL12 Expression Is Linked to NADPH Oxidase AtRBOHD/F-Driven ROS Production

ATL12 expression is highly induced after two hours of chitin treatment, suggesting that ATL12 may be involved in the early events leading to chitin elicitor triggered immunity. Reactive oxygen species (ROS) are very important molecules produced in plant cells early in the infection process when plants are facing pathogen invasion or during abiotic stress that causes significant local cell damage $[1,13,24]$. Since the ROS response is crucial for disease resistance, and to determine if ATL12 expression is related to ROS production during pathogen infection, Col-0, at112 T-DNA insertional mutants and an ATL12 overexpression line were inoculated with powdery mildew or treated with $100 \mathrm{mg} / \mathrm{mL}$ of chitin. Infected leaves of each mutant were double stained with diaminobenzidine (DAB) to visualize hydrogen peroxide $\left(\mathrm{H}_{2} \mathrm{O}_{2}\right)$ and with Coomassie Blue to detect fungal hyphae and conidiophores. Compared to Col-0 wild type, all three atl12 T-DNA insertional mutant lines showed less ROS production (Figure 6A(a)). To determine if ATL12 plays a role in the induction of ROS, leaves of Col-0, the insertional mutants of atl12 and the ATL12 over-expression line were detached and treated with $100 \mathrm{mg} / \mathrm{mL}$ of chitin for two hours. As shown in Figure 6A(b), ROS production showed no significant differences among Col-0 wild type, atl12 T-DNA insertional mutant lines, and the overexpression lines without chitin treatment. While mutants of atl12 (atl12, atl12a, and atl12b) displayed less ROS generation after chitin treatment compared to Col-0 wild type, the overexpression lines of ATL12 had significantly more ROS generation, (Figure 6A(c)). These data suggest that ATL12 may be responsible for ROS production at early timepoints for effective defense against powdery mildew.

Previous studies have shown that chitin receptor-mediated ROS production is linked to the Arabidopsis thaliana respiratory burst oxidase homolog D and $\mathrm{F}$ genes $(A t R B O H D / F)$, two NADPH oxidases in Arabidopsis [13,25]. Our previous results have shown that ATL12 may be responsible for ROS production in early defense responses against powdery mildew infection. To confirm if AtRBOHD expression is induced at the early timepoints. Wild-type Col-0 plants were treated with $100 \mathrm{mg} / \mathrm{mL}$ chitin and tissue samples were harvested at four early time points: $1 \mathrm{~h}, 2 \mathrm{~h}, 4 \mathrm{~h}, 8 \mathrm{~h}, 16 \mathrm{~h}$ and $24 \mathrm{~h}$. AtRBOHD gene expression was determined using qRT-PCR. The result is shown in Figure 6B. AtRBOHD is highly induced by chitin treatment and at the very early time point $(1 \mathrm{~h})$, the expression reached a peak at $2 \mathrm{~h}$ and then started to drop at $4 \mathrm{~h}$ and $8 \mathrm{~h}$. At $24 \mathrm{~h}$ after chitin treatment, AtRBOHD expression reached to another peak. Then to determine if ATL12-mediated ROS production is related to $A t R B O H D / F$ expression, T-DNA insertion mutants, overexpression line, and Col-0 wild type plants were treated with $100 \mathrm{mg} / \mathrm{mL}$ chitin for $2 \mathrm{~h}$ or treated with MS medium as mock control, and expression of ATL12, MAPK3, AtRBOHD, AtRBOHF, and $A C T 2$ were monitored via RT-PCR. The AtRBOHD, AtRBOHF, and MAPK3 expressions have no significant difference among atl12 mutants, overexpression lines and wild type. As shown in Figure 6C, AtRBOHD and AtRBOHF expression is impaired in all three atl12 mutant lines, while both $A t R B O H D / F$ are upregulated in the ATL12 overexpression line, suggesting that $A T L 12$ expression may be responsible for $A t R B O H D / F$ expression.

To investigate the detailed relationship between ATL12 and AtRBOHD/F induced ROS production, insertional mutants of atrbohd and atrbohf were tested to determine if loss of AtRBOHD/F affected ATL12 expression. atrbohd and atrbohf mutants are verified by PCR based on methods mentioned previously, the result is shown in Figure 6D. Under normal condition, there are no significant differences of ATL12 and MAPK3 mRNA expression in atrbohd/f mutants, as shown in Figure 6E. AtRBOHD/F and MAPK3 expression were significantly decreased in atrbohd/f mutants after chitin treatment, as shown in Figure 6E, while the expression of ATL12 was not affected in either atrbohd or atrbohf mutants. This suggests that chitin induced ATL12 expression may link to the AtRBOHD/F-related signal transduction pathway. Taken together, these results suggest that $A T L 12$ is involved in $A t R B O H D / F$-mediated defense responses and that the expression of $A T L 12$ and $A t R B O H D / F$ is needed for effective defense against powdery mildew infection. 
A

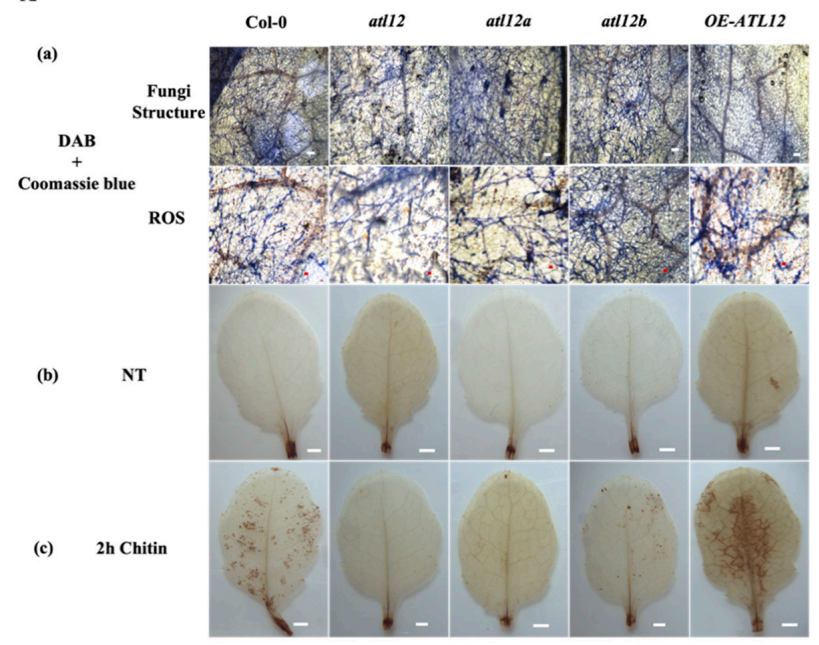

B
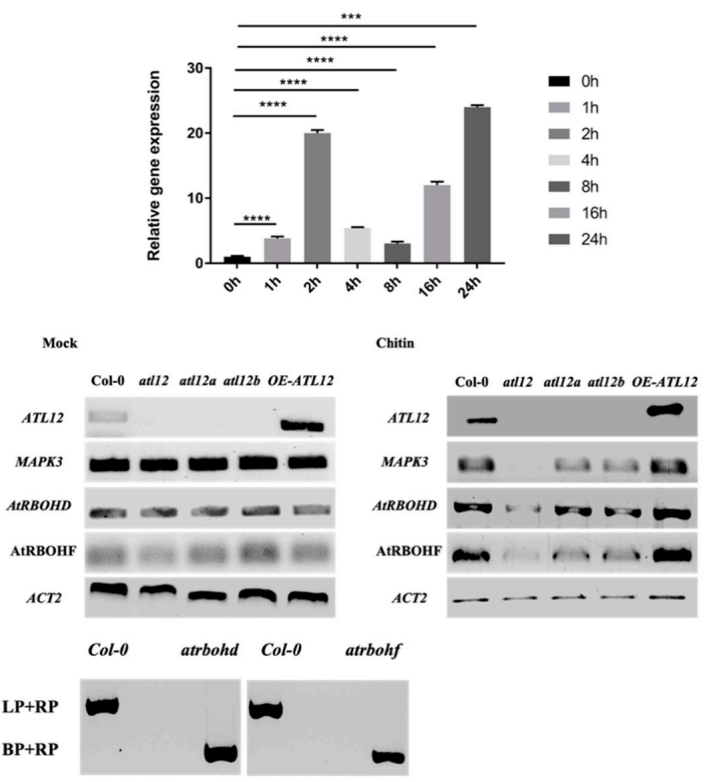

E
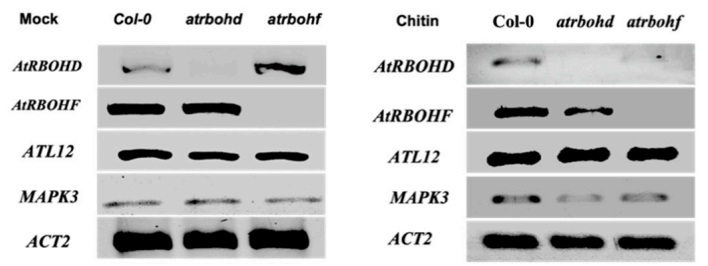

Figure 6. ATL12 is responsible for $A t R B O H D / F$-dependent ROS production in response to chitin. (A). (a) DAB and Coomassie blue staining of plants in response to fungal treatment. Blue line indicated fungal hyphae, and brown precipitate indicated ROS. (b) DAB staining of different seedlings without chitin treatment; (c) DAB staining of plants treated with $100 \mathrm{mg} / \mathrm{mL}$ chitin for $2 \mathrm{~h}$. Scale bar indicated $1 \mathrm{~mm}$. (B). Temporal expression level of AtRBOHD mRNA expression after chitin treatment via qRT-PCR. (C). RT-PCR analysis of ATL12, MAPK3, AtRBOHD, and AtRBOHF expression in wild-type, atl12 mutants and overexpression (OE) lines under normal condition(mock) and after chitin treatment. (D). Amplification of ATL12 in genomic DNA from the wild type, atrbohd and atrbohf. LP and RP are mutant-specific gene primers. BP is border primer in T-DNA insertional chunk in mutant. (E). RT-PCR analysis of AtRBOHD, AtRBOHF, ATL12, and MAPK3 expression in mutant atrbohd, atrbohf, and Col-0 plants under normal conditions (mock control) and after chitin treatment. Experiments were repeated three times. The white and red scale bar indicates $1 \mathrm{~mm} .{ }^{* *}$ indicates $p<0.001$ and $^{* * * *}$ indicates $p<0.0001$. 


\subsection{ATL12 May Act Downstream of Chitin-Mediated MAP Kinase 3 (MAPK3) Signaling}

One of the major events occurring during the early chitin-induced immune response is the activation of a MAPK cascade [13]. Our results show that ATL12 expression is highly induced at early time points after chitin treatment, which suggests that ATL12 may be involved in some of the earliest events during the chitin elicitor induced immune response. To determine if ATL12 expression is linked to the activation of the MAPK cascade, several TDNA insertional mutants in known chitin-mediated signaling pathway genes (cerk1, mapk3, wrky53) were obtained and tested. The confirmation of all homozygous T-DNA insertion mutant lines is shown in Supplementary Materials Figure S3. Each mutant line was treated with $100 \mathrm{mg} / \mathrm{mL}$ chitin for $2 \mathrm{~h}$ and expression levels were determined via RT-PCR and qRT-PCR. ATL12 expression was downregulated in both cerk1 and mapk3 after treatment with chitin, while ATL12 expression was not affected in wrky53 (Figure 7A). The expression of CERK1 was downregulated in atl12 and mapk3. Additionally, MAPK3 expression was impaired in both atl12 and cerk1 and slightly upregulated in wrky53 (Figure 7A). As expected, WRKY53 expression was downregulated in both the cerk1 and mapk3 mutants. Taken together these data indicate that ATL12 is linked to the chitin-mediated signaling pathway through the action of the chitin induced MAPK3 cascade.

Previous research suggested that knock out mutants in CERK1 completely lost the ability to induce ROS and activate the MAPK cascades in chitin-induced defense [12]. Our results suggest that $A T L 12$-induced ROS production is necessary for $A t R B O H D / F$ expression during this response. To confirm the relationship between ATL12 expression, ROS production and MAPK cascade activation, cerk1, mapk3, and atl12 were treated with $100 \mathrm{mg} / \mathrm{mL}$ chitin for $2 \mathrm{~h}$ and expression levels were monitored via qRT-PCR. ATL12 expression was downregulated in cerk1, mapk3, atrbohd, and atrbohf (Figure 7B). The expression of CERK1 was downregulated in both atl12 and mapk3 and MAPK3 expression was impaired in atl12 and cerk1 (Figure 7B). AtROBHD and AtRBOHF gene expression were both downregulated in atl12, mapk3 and cerk1, suggesting that ATL12 may function as a mediator between chitin-elicitor triggered immunity and AtRBOHD/F-mediated defense responses.

\subsection{Influence of $S A-, J A$ - and Chitin-Mediated Pathways on ATL12 Expression}

The salicylic acid (SA)-mediated pathway is involved in plant defense against biotrophic pathogens, while jasmonic acid (JA, MeJA) is predominantly linked with defense against necrotrophic pathogens [26]. To determine if the expression of ATL12 was not only induced by chitin but also involved in the SA-, and JA- mediated signaling pathways, we treated Col-0 plants with $100 \mathrm{mg} / \mathrm{mL}$ chitin, $100 \mu \mathrm{M}$ MeJA or $2 \mathrm{mM}$ salicylic acid for $2 \mathrm{~h}$ and monitored the expression of ATL12, and marker genes in each signaling pathway (PDF1.2 (JA), PR1 (SA), MAPK3 (chitin)) using qRT-PCR. As shown in Figure 8A, the expression of ATL12 is highly induced by chitin treatment and is also induced by both MeJA and SA treatment. MAPK3 was highly induced by chitin treatment and was slightly upregulated in the SA treatment but expression of MAPK3 was not affected by MeJA treatment (Figure 8A). As expected, $P R 1$ was highly induced by SA treatment and slightly upregulated above control levels in the MeJA treatment and PDF1.2 was highly induced by JA treatment and was strongly downregulated in the SA treatment (Figure 8A). Interestingly, the expression of both PR1 and PDF1.2 showed no significant difference between the chitin treatment and normal conditions. From these data, it indicated that ATL12 expression is highly induced by chitin treatment and is also enhanced by JA and SA treatment, which suggests that ATL12 may be involved in crosstalk between SA-, JA- and chitin-mediated signaling pathways. 
A

\section{Col-0 at112 cerk1 mapk3 wrky53}

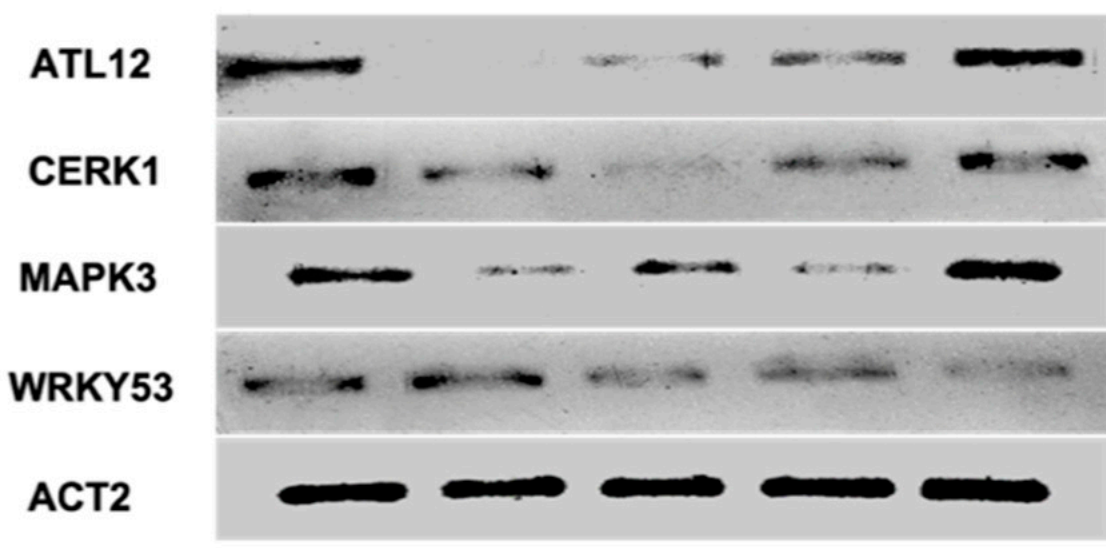

B

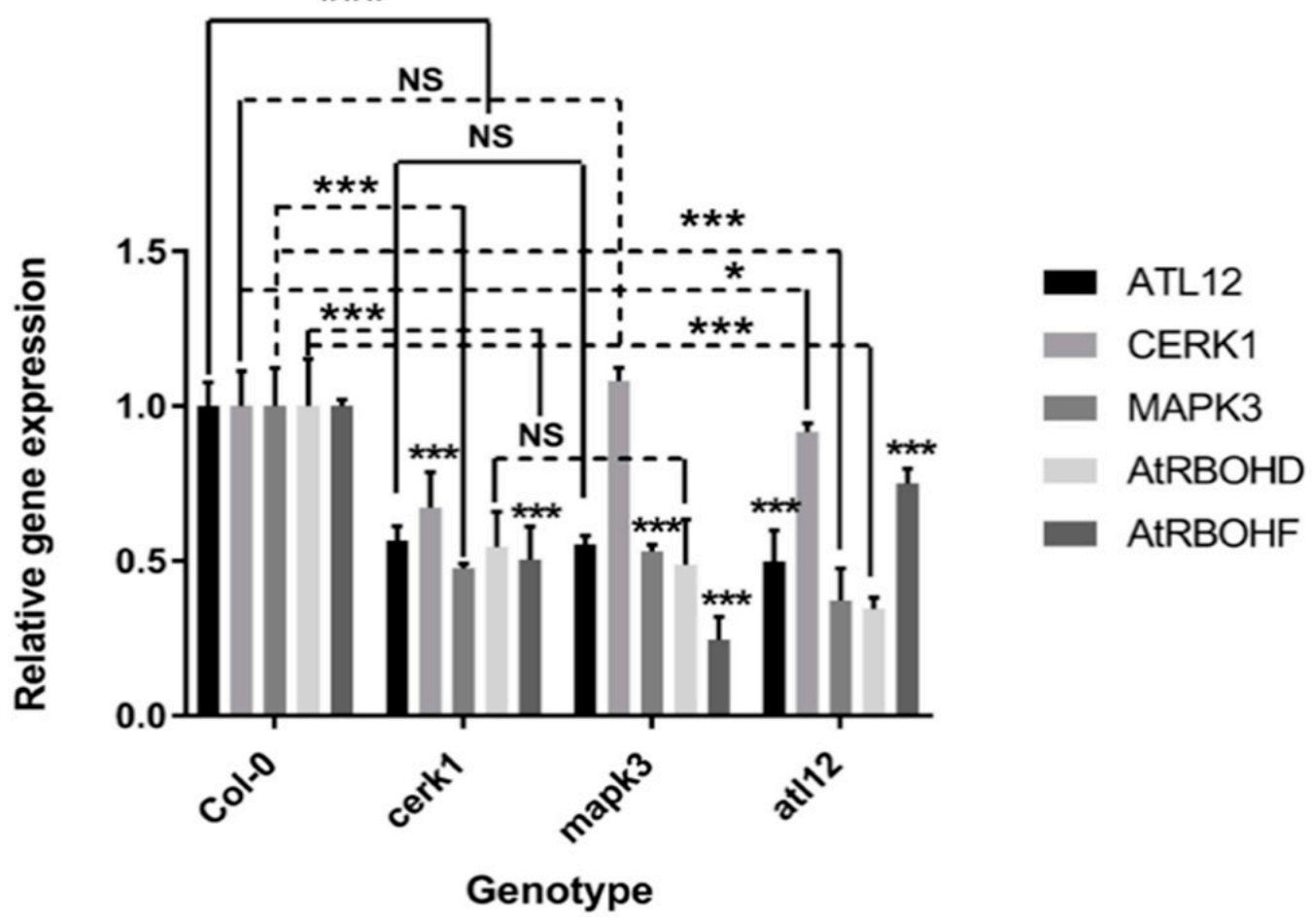

Figure 7. ATL12 is involved with the chitin-mediated signaling pathway through MAP kinase 3 (MAPK3) cascades. (A). RT-PCR analysis of marker gene expression in wildtype and mutants. (B). qRT-PCR analysis of ATL12, CERK1, MAPK3, AtRBOHD, and AtRBOHF expression in wildtype and mutants. Experiments were repeated three times. ${ }^{* * *}$ indicates $p<0.001$; ${ }^{*}$ indicates $p<0.05$ and NS indicates not significant. 


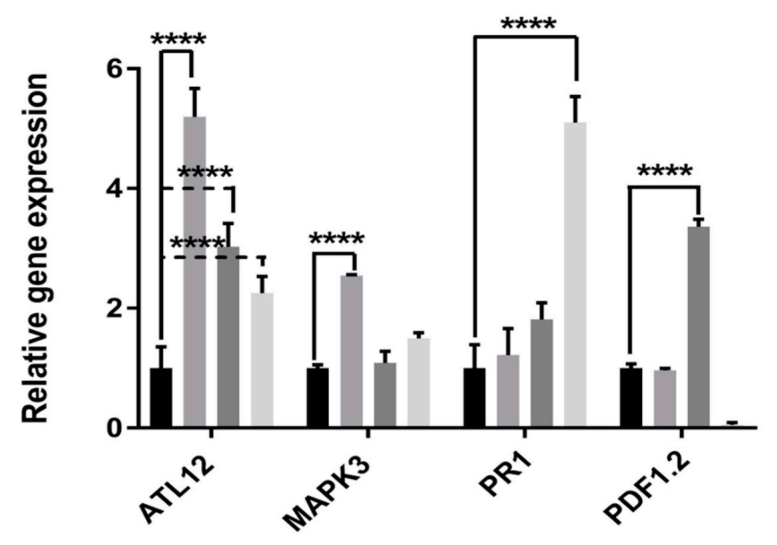

B

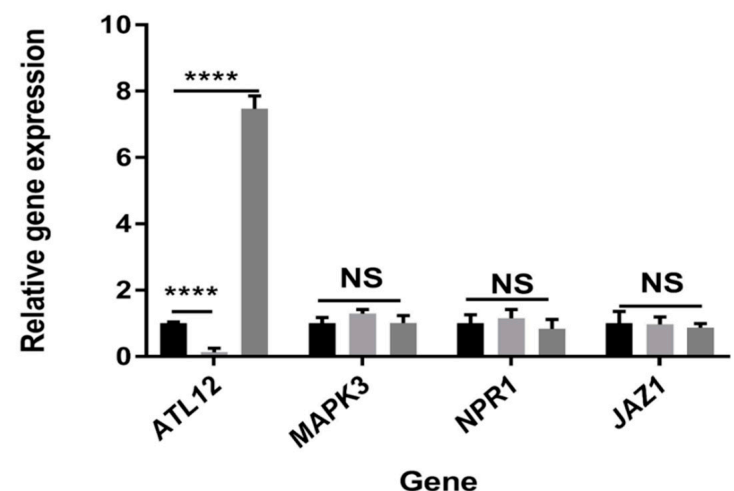

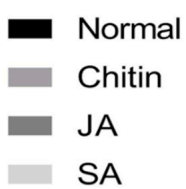

SA

C

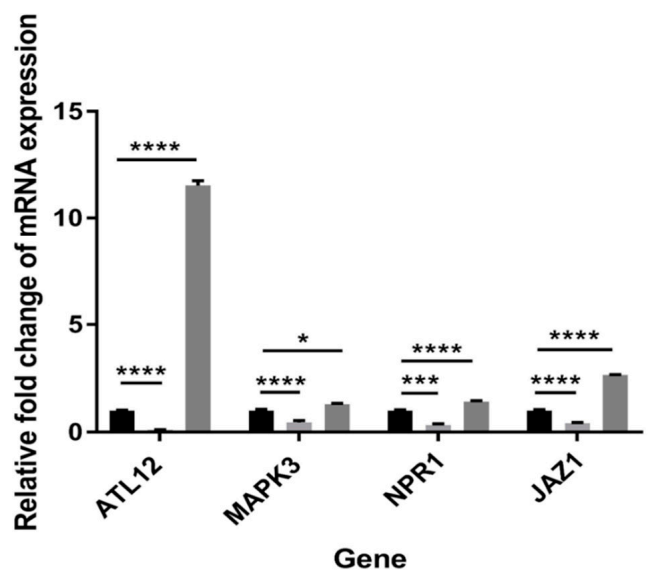

- Col-O

at/12

- OE-ATL12

Col-0 2h Chitin

- atl12 2h Chitin

- OE-ATL12 2h Chitin

Figure 8. Influence of SA-, JA-, and Chitin-mediated pathways on ATL12 expression (A). qRT-PCR analysis of marker gene expression in response to $100 \mathrm{mg} / \mathrm{mL}$ chitin, $100 \mu \mathrm{M}$ MeJA, and $2 \mathrm{mM}$ Salicylic acid for $2 \mathrm{~h}$ and ATL12, internal control beta-actin and marker genes for each signaling pathway were determined. (B). qRT-PCR analysis of marker gene expression under normal conditions. (C). qRT-PCR analysis of marker gene expression in response to $100 \mathrm{mg} / \mathrm{mL}$ chitin for $2 \mathrm{~h}$ and ATL12, internal control beta-actin and marker genes for each signaling pathway expression were determined. NS indicated no significance. Asterisks indicate statically significant differences between the samples treated and untreated, according to the One-way ANOVA analysis and multiple comparisons postTukey's test. The whole experiments were repeated three times. ${ }^{* * *}$ indicated $p<0.0001,{ }^{* * *}$ indicated $p<0.001$, and * indicated $p<0.05$. 
Since ATL12 is not only induced by chitin but is also induced by SA and JA treatment, we wanted to further investigate how ATL12 contributes to SA and JA signaling during chitin-triggered immune responses. Col-0 wild type, atl12 and overexpression ATL12 seedlings were treated with $100 \mathrm{mg} / \mathrm{mL}$ chitin for $2 \mathrm{~h}$ and the expression levels of three marker genes, MAPK3 (chitin), Nonexpressor of PR genes 1 (NPR1, SA marker) and Jasmonte zim-domain protein 1 (JAZ1, JA marker) were determined. As shown in Figure 8B,C, atl12 showed less NPR1 and JAZ1 expression compared to Col-0 wild type, while overexpression of ATL12 increased the expression of NPR1 and JAZ1. These data further suggest that ATL12 is involved in both SA- and JA-mediated signaling during chitin triggered immune responses.

\section{Discussion}

4.1. ATL12 Is a Putative E3 Ubiquitin Ligase That Is Involved in Defense Responses against Fungal Pathogens

The plant $26 \mathrm{~S}$ proteasome/ubiquitination is crucial in response to stress and in degrading misfolded proteins [18]. The $26 \mathrm{~S}$ proteasome system is also key in regulating signals in plant innate immunity [27-29]. Great attention has been given to the plant 26S proteasome/ubiquitination system in the past decade, especially to the discovery and characterization of E3 ubiquitin ligases [17,18]. In Arabidopsis, there are over 450 predicted proteins that contain one or more RING domains [30], which are predicted to have E3 ubiquitin ligase activity. ATL12 belongs to ATL2 gene family and it appears that many of the members of the ATL2 gene family most likely encode RING-H2 zinc-finger domain proteins with at least six cysteines and three histidine amino acids. In addition, all proteins in the ATL2 family have at least one transmembrane domain and 4 of them have a PEST domain. While most of the functions of all the ATL2 family genes are still unknown, there are some studies shown that $A T L$ family genes are involved in chitin elicitor triggered immune response or defense responses against fungal pathogens [26]. For example, ATL2 is one gene of a multigene ATL family, which encoded highly conserved RING-H2 zinc-finger proteins that may function as E3 ubiquitin ligases, and ATL2 expression is highly induced with chitin [22]. Some early chitin-response genes and known pathogenesis-related genes such as NPR1 are induced in constitutive expression of the ATL2 gene mutants [23]. ATL9, one gene belongs to the ATL2 gene family that encoded a RING domain contained zinc finger protein with E3 ubiquitin ligase activity has been proven to be involved in Chitinand NADPH oxidase-mediated defense responses [11,31].

Here, we have shown that ATL12 encodes a RING-H2 zinc-finger domain protein that may functions as RING-type E3 ubiquitin ligase and is highly induced by chitin treatment and fungal infection. Our results have shown that ATL12 is involved with resistance against G. cichoracearum. ATL12 mRNA expression is highly induced by chitin elicitor treatment at early time points ( $2 \mathrm{~h}$ ). In addition, ATL12 is induced by JA and SA treatment but displays differential expression patterns. Taken all together, it appears that ATL12 may be involved in the early response of chitin elicitor triggered defense response and engaged in SA or JA mediated defense response pathways. However, the detailed molecular mechanisms of ATL12 in chitin elicitor triggered defense responses and SA or JA mediated defense response pathways remain unknown. Our future studies will focus on the ATL12's possible interacting partners within chitin-mediated signaling pathway using the high-throughput sequencing or bimolecular fluorescence complementation-based cDNA library screening to help us better understand its role in plant innate immunity and defense responses against fungal pathogens.

\subsection{ATL12 Is Involved in Both NADPH Oxidase-Mediated and Chitin Mediated Defense Responses}

Reactive oxygen species (ROS) are very important molecules produced in plant cells when plants are facing pathogen infection or abiotic stress. High concentrations of ROS are harmful to plant species and cause significant oxidative damage or even cell death if not cleared by the ROS scavenging system [32-34]. However, ROS when present at low 
levels within cells are recognized as important signaling molecules, which involved in normal plant growth [35] and responses to biotic and abiotic stresses [34,36]. In Arabidopsis thaliana, ROS generation mediated by the activation of NADPH oxidase $(\mathrm{RBOH})$ is well studied and has been shown to be involved with fungal defense $[37,38]$ and abiotic stresses tolerance [39-41].

Our results showed that mutants of atl12 have less ROS generation after chitin treatment compared to Col- 0 wild type, while overexpression of ATL12 has more ROS generation. At the same time, we observed that the expression of $A t R B O H D$ and AtRBOHF is downregulated in the mutant of atl12 and upregulated in overexpression lines. Our previous research showed that both atrbohd, and atrbohf mutants were more susceptible than wild type to G. cichoracearum and relatively low levels of hydrogen peroxide accumulation were detected $[11,34,38]$. Considering these results together, we believe that the expression of ATL12 is related to AtRBOHD and AtRBOHF medicated ROS generation after chitin treatment. The ATL12 expression involved NADPH oxidase-mediated signaling is required for defense against $G$. cichoracearum infection. Moreover, to further study the relationship between ATL12, with AtRBOHD/F-induced ROS production, we treated the mutants of atrbohd and atrbohf with $100 \mathrm{mg} / \mathrm{mL}$ chitin and RT-PCR indicated that the expression of ATL12 is not affected in either the atrbohd or atrbohf mutant, suggesting that ATL12 may act upstream of $A t R B O H D / F$-related signal transduction. Previous studies have shown that in knock out (KO) mutants of cerk1, the KO mutant completely lost the ability to respond to chitin and activate chitin-associated MAPKs, generate ROS, and activate defense-related gene expression [13-15]. In our results, we noted that the expression of ATL12 is downregulated in the KO mutant of cerk1. Taken together, these data suggest that ATL12 is integral in both chitin-mediated defense responses and NADPH-mediated ROS production. ATL12 may serve as a connection between these two defense-signaling pathways with ATL12 acting as one of the key regulators. The detailed mechanism linking ATL12 expression with chitin signaling and NADPH-mediated ROS production has yet to be elucidated and will be the subject of future investigation.

\subsection{Possible Role of ATL12 in Hormone, NADPH Oxidase-Mediated and Chitin-Mediated Defense}

In this study, we noted that ATL12 is highly induced by chitin treatment and fungal invasion and it also appears that ATL12 may act downstream of chitin-mediated signaling pathway, via the MAP kinase 3 (MAPK3) signaling cascade. Additionally, we showed that ATL12 is linked to ROS production and RT-PCR indicated that ATL12-related ROS production is dependent on expression of both AtRBOHD and AtRBOHF. Moreover, ATL12 appears to act upstream of $A t R B O H D / F$-related signaling in Arabidopsis. qRT-PCR results showed that ATL12 expression is affected by JA and SA treatment, suggesting that ATL12 may act in SA- and JA-mediated defense signaling [42]. However, further studies are required to unravel the complete role of ATL12 in hormone-mediated defense responses. Considering the data collectively, we hypothesize that ATL12 may be involved in crosstalk or coordination between the JA- and SA-mediated, NADPH oxidase-mediated, and chitin-mediated signaling pathways. A possible model demonstrating the role ofATL12 in mediating information flow between these diverse pathways is shown in Figure 9. The figure was created with BioRender. Overall the data from the current study indicate that ATL12 may be involved in a broader spectrum plant defense response. Future studies to determine ATL12's interacting partners that link this E3 ligase with the JA- and SA-induced defense responses, NADPH oxidase-mediated signaling and the current model of chitinmediated signaling will provide us with a more complete picture of the links between chitin signaling and a robust defense response against fungal pathogens. 


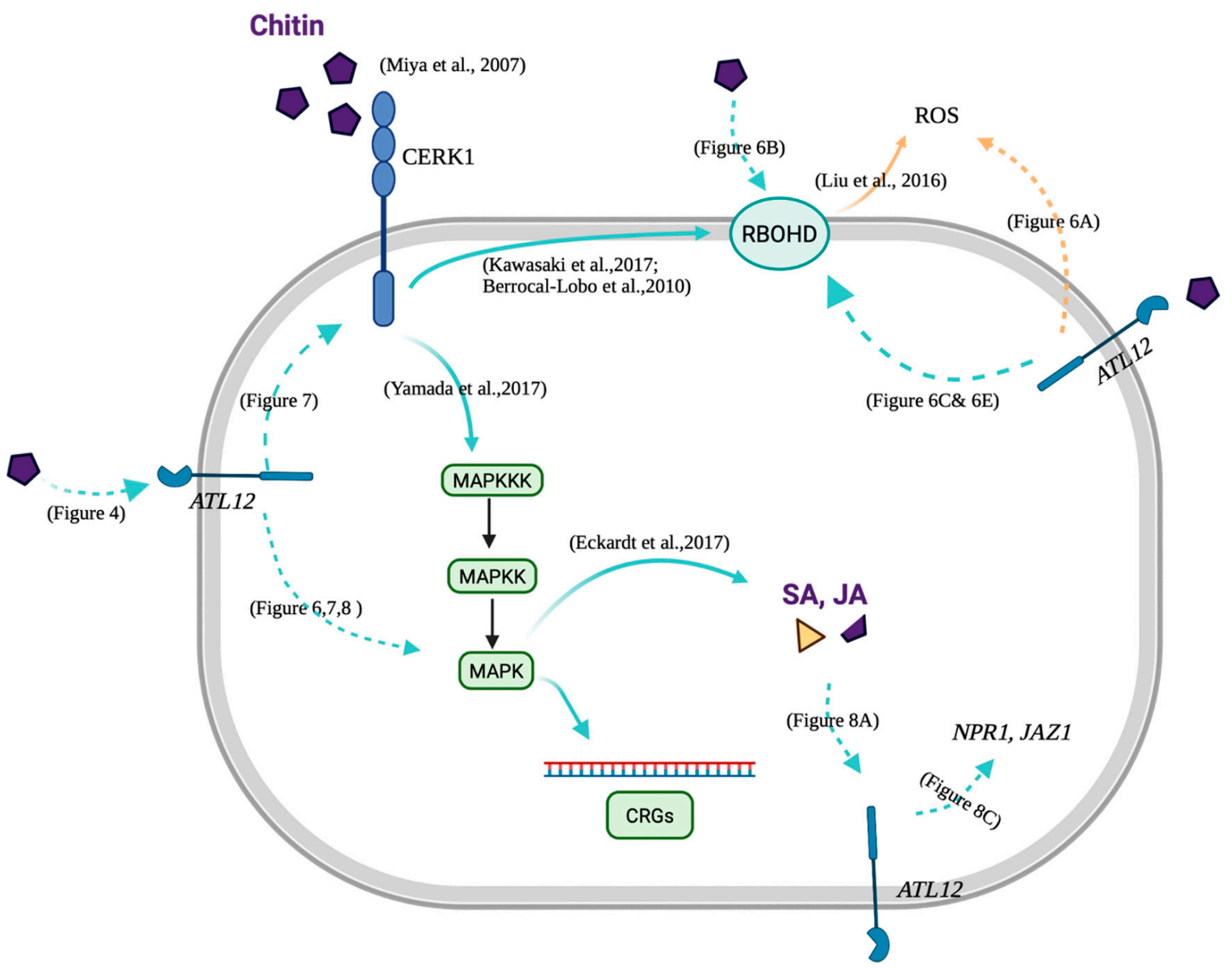

Figure 9. A possible model of ATL12 function in the hormone, NADPH oxidase-mediated and the chitin-mediated defense. ATL12 is at the downstream of chitin-mediated signaling pathway, through the MAP kinase 3 (MAPK3) cascade. Besides, ATL12 is related to ROS generation and may act at the upstream of ATRBOHD/F-related signaling transduction pathway. Moreover, ATL12 may be involved in the SA-, and JA-mediated signaling pathway [42]. The figure with created with BioRender.com with license agreement number DV2337X56K.

Supplementary Materials: The following are available online at https: / www.mdpi.com/article / 10.3390/jof7100883/s1, Figure S1: The complete cDNA and amino acid sequences of the ATL12; Figure S2: Screening for homozygous T-DNA insertion mutants and overexpression lines; Figure S3: Screening for homozygous cerk1, mapk3 and wrky53 mutants.

Author Contributions: Conceptualization, F.K. and K.M.R.; Data curation, F.K.; Formal analysis, F.K.; Investigation, F.K. and K.M.R.; Methodology, F.K.; Project administration, F.K. and K.M.R.; Resources, F.K.; Software, F.K.; Supervision, F.K. and K.M.R.; Validation, F.K. and T.G.; Visualization, F.K. and T.G.; Writing—original draft, F.K.; Writing—review \& editing, F.K., T.G. and K.M.R. All authors have read and agreed to the published version of the manuscript.

Funding: This research received no external funding.

Institutional Review Board Statement: Not applicable.

Informed Consent Statement: Not applicable.

Data Availability Statement: Data is contained within the article or supplementary material.

Acknowledgments: We thank all the members of the Ramonell lab for helpful discussions and review of the manuscript. We also thank Kim Lackey from Department of Biological Sciences at the University of Alabama for help with the microscopy.

Conflicts of Interest: The authors declare no conflict of interest. 


\section{References}

1. Bigeard, J.; Colcombet, J.; Hirt, H. Signaling Mechanisms in Pattern-Triggered Immunity (PTI). Mol. Plant 2015, 8, 521-539. [CrossRef]

2. Fones, H.N.; Bebber, D.P.; Chaloner, T.M.; Kay, W.T.; Steinberg, G.; Gurr, S.J. Threats to global food security from emerging fungal and oomycete crop pathogens. Nat. Food 2020, 1, 332-342. [CrossRef]

3. Micali, C.; Göllner, K.; Humphry, M.; Consonni, C.; Panstruga, R. The Powdery Mildew Disease of Arabidopsis: A Paradigm for the Interaction between Plants and Biotrophic Fungi. Arab. Book 2008, 6, e0115. [CrossRef] [PubMed]

4. Petutschnig, E.K.; Jones, A.M.; Serazetdinova, L.; Lipka, U.; Lipka, V. The Lysin Motif Receptor-like Kinase (LysM-RLK) CERK1 Is a Major Chitin-binding Protein in Arabidopsis thaliana and Subject to Chitin-induced Phosphorylation. J. Biol. Chem. 2010, 285, 28902-28911. [CrossRef]

5. Jones, J.D.G.; Dangl, J.L. The plant immune system. Nature 2006, 444, 323-329. [CrossRef]

6. Mishra, A.K.; Sharma, K.; Misra, R.S. Elicitor recognition, signal transduction and induced resistance in plants. J. Plant Interact. 2012, 7, 95-120. [CrossRef]

7. Ali, G.S.; Reddy, A. PAMP-triggered immunity: Early events in the activation of FLAGELLIN SENSITIVE2. Plant Signal. Behav. 2008, 3, 423-426. [CrossRef]

8. Eyin, H.; Edu, Y.; Edong, Z. Chitin Oligosaccharide and Chitosan Oligosaccharide: Two Similar but Different Plant Elicitors. Front. Plant Sci. 2016, 7, 522. [CrossRef] [PubMed]

9. Chang, Y.-H.; Yan, H.-Z.; Liou, R.-F. A novel elicitor protein from Phytophthora parasitica induces plant basal immunity and systemic acquired resistance. Mol. Plant Pathol. 2015, 16, 123-136. [CrossRef] [PubMed]

10. O'Brien, J.A.; Daudi, A.; Butt, V.S.; Bolwell, G.P. Reactive oxygen species and their role in plant defence and cell wall metabolism. Planta 2012, 236, 765-779. [CrossRef]

11. Berrocal-Lobo, M.; Stone, S.; Yang, X.; Antico, J.; Callis, J.; Ramonell, K.M.; Somerville, S. ATL9, a RING Zinc Finger Protein with E3 Ubiquitin Ligase Activity Implicated in Chitin- and NADPH Oxidase-Mediated Defense Responses. PLoS ONE 2010, 5, e14426. [CrossRef] [PubMed]

12. Takenaka, Y.; Nakano, S.; Tamoi, M.; Sakuda, S.; Fukamizo, T. Chitinase Gene Expression in Response to Environmental Stresses in Arabidopsis thaliana: Chitinase Inhibitor Allosamidin Enhances Stress Tolerance. Biosci. Biotechnol. Biochem. 2009, 73, $1066-1071$. [CrossRef]

13. Miya, A.; Albert, P.; Shinya, T.; Desaki, Y.; Ichimura, K.; Shirasu, K.; Narusaka, Y.; Kawakami, N.; Kaku, H.; Shibuya, N. CERK1, a LysM receptor kinase, is essential for chitin elicitor signaling in Arabidopsis. Proc. Natl. Acad. Sci. USA 2007, 104, 19613-19618. [CrossRef] [PubMed]

14. Yamada, K.; Yamaguchi, K.; Yoshimura, S.; Terauchi, A.; Kawasaki, T. Conservation of Chitin-Induced MAPK Signaling Pathways in Rice and Arabidopsis. Plant Cell Physiol. 2017, 58, 993-1002. [CrossRef]

15. Kawasaki, T.; Yamada, K.; Yoshimura, S.; Yamaguchi, K. Chitin receptor-mediated activation of MAP kinases and ROS production in rice and Arabidopsis. Plant Signal. Behav. 2017, 12, e1361076. [CrossRef] [PubMed]

16. Wan, J.; Zhang, X.-C.; Neece, D.; Ramonell, K.M.; Clough, S.; Kim, S.-Y.; Stacey, M.G.; Stacey, G. A LysM Receptor-Like Kinase Plays a Critical Role in Chitin Signaling and Fungal Resistance in Arabidopsis. Plant Cell 2008, 20, 471-481. [CrossRef]

17. Craig, A.; Ewan, R.; Mesmar, J.; Gudipati, V.; Sadanandom, A. E3 ubiquitin ligases and plant innate immunity. J. Exp. Bot. 2009, 60, 1123-1132. [CrossRef]

18. Dielen, A.-S.; Badaoui, S.; Candresse, T.; German-Retana, S. The ubiquitin/26S proteasome system in plant-pathogen interactions: A never-ending hide-and-seek game. Mol. Plant Pathol. 2010, 11, 293-308. [CrossRef]

19. Sadanandom, A.; Bailey, M.; Ewan, R.; Lee, J.; Nelis, S. The ubiquitin-proteasome system: Central modifier of plant signalling. New Phytol. 2012, 196, 13-28. [CrossRef] [PubMed]

20. Ausubel, F.M. Are innate immune signaling pathways in plants and animals conserved? Nat. Immunol. 2005, 6, 973-979. [CrossRef]

21. Suh, J.Y.; Kim, S.J.; Oh, T.R.; Cho, S.K.; Yang, S.W.; Kim, W.T. Arabidopsis Tóxicos en Levadura 78 (AtATL78) mediates ABA-dependent ROS signaling in response to drought stress. Biochem. Biophys. Res. Commun. 2016, 469, 8-14. [CrossRef]

22. Serrano, M.; Guzmán, P. Isolation and gene expression analysis of Arabidopsis thaliana mutants with constitutive expression of ATL2, an early elicitor-response RING-H2 zinc-finger gene. Genetics 2004, 167, 919-929. [CrossRef] [PubMed]

23. Clough, S.J.; Bent, A.F. Floral dip: A simplified method for Agrobacterium-mediated transformation of Arabidopsis thaliana. Plant J. 1998, 16, 735-743. [CrossRef]

24. Zhou, Z.; Zhao, Y.; Bi, G.; Liang, X.; Zhou, J.-M. Early signalling mechanisms underlying receptor kinase-mediated immunity in plants. Philos. Trans. R. Soc. B Biol. Sci. 2019, 374, 20180310. [CrossRef] [PubMed]

25. Glazebrook, J. Contrasting Mechanisms of Defense against Biotrophic and Necrotrophic Pathogens. Annu. Rev. Phytopathol. 2005, 43, 205-227. [CrossRef] [PubMed]

26. Serrano, M.; Parra, S.; Alcaraz, L.D.; Guzmán, P. The ATL Gene Family from Arabidopsis thaliana and Oryza sativa Comprises a Large Number of Putative Ubiquitin Ligases of the RING-H2 Type. J. Mol. Evol. 2006, 62, 434-445. [CrossRef]

27. Dong, W.; Nowara, D.; Schweizer, P. Protein Polyubiquitination Plays a Role in Basal Host Resistance of Barley. Plant Cell 2006, 18, 3321-3331. [CrossRef] [PubMed] 
28. Manzano, C.; Abraham, Z.; López-Torrejón, G.; Del Pozo, J.C. Identification of ubiquitinated proteins in Arabidopsis. Plant Mol. Biol. 2008, 68, 145-158. [CrossRef]

29. Stone, S.L. The role of ubiquitin and the $26 \mathrm{~S}$ proteasome in plant abiotic stress signaling. Front. Plant Sci. 2014, 5, 135. [CrossRef]

30. Dreher, K.; Callis, J. Ubiquitin, Hormones and Biotic Stress in Plants. Ann. Bot. 2007, 99, 787-822. [CrossRef]

31. Deng, F.; Guo, T.; Lefebvre, M.; Scaglione, S.; Antico, C.J.; Jing, T.; Yang, X.; Shan, W.; Ramonell, K.M. Expression and regulation of ATL9, an E3 ubiquitin ligase involved in plant defense. PLoS ONE 2017, 12, e0188458. [CrossRef]

32. Wang, J.; Nan, N.; Shi, L.; Li, N.; Huang, S.; Zhang, A.; Liu, Y.; Guo, P.; Liu, B.; Xu, Z. Arabidopsis BRCA1 represses RRTF1mediated ROS production and ROS-responsive gene expression under dehydration stress. New Phytol. 2020, 228, 1591-1610. [CrossRef]

33. Davies, D.R.; Bindschedler, L.; Strickland, T.S.; Bolwell, G.P. Production of reactive oxygen species in Arabidopsis thaliana cell suspension cultures in response to an elicitor from Fusarium oxysporum: Implications for basal resistance. J. Exp. Bot. 2006, 57, 1817-1827. [CrossRef]

34. Evans, N.H.; McAinsh, M.R.; Hetherington, A.; Knight, M. ROS perception in Arabidopsis thaliana: The ozone-induced calcium response. Plant J. 2005, 41, 615-626. [CrossRef] [PubMed]

35. Tsukagoshi, H.; Busch, W.; Benfey, P.N. Transcriptional Regulation of ROS Controls Transition from Proliferation to Differentiation in the Root. Cell 2010, 143, 606-616. [CrossRef] [PubMed]

36. Huang, H.; Ullah, F.; Zhou, D.-X.; Yi, M.; Zhao, Y. Mechanisms of ROS Regulation of Plant Development and Stress Responses. Front. Plant Sci. 2019, 10, 800. [CrossRef]

37. Derksen, H.; Rampitsch, C.; Daayf, F. Signaling cross-talk in plant disease resistance. Plant Sci. 2013, 207, 79-87. [CrossRef]

38. Liu, Y.; He, C. Regulation of plant reactive oxygen species (ROS) in stress responses: Learning from AtRBOHD. Plant Cell Rep. 2016, 35, 995-1007. [CrossRef] [PubMed]

39. Li, X.; Zhao, J.; Sun, Y.; Li, Y. Arabidopsis thaliana CRK41 negatively regulates salt tolerance via $\mathrm{H}_{2} \mathrm{O}_{2}$ and $\mathrm{ABA}$ cross-linked networks. Environ. Exp. Bot. 2020, 179, 104210. [CrossRef]

40. Prasad, T.K.; Anderson, M.D.; Martin, B.A.; Stewart, C.R. Evidence for Chilling-Induced Oxidative Stress in Maize Seedlings and a Regulatory Role for Hydrogen Peroxide. Plant Cell 1994, 6, 65-74. [CrossRef]

41. You, J.; Chan, Z. ROS Regulation during Abiotic Stress Responses in Crop Plants. Front. Plant Sci. 2015, 6, 1092. [CrossRef]

42. Eckardt, N.A. The Plant Cell Reviews Plant Immunity: Receptor-Like Kinases, ROS-RLK Crosstalk, Quantitative Resistance, and the Growth/Defense Trade-Off. Plant Cell 2017, 29, 601-602. [CrossRef] [PubMed] 